\title{
La negociación centro-región en Chile: realidad o mito - El caso de la región de Los Lagos*
}

\author{
Pablo Aurelio Monje Reyes**
}

Sumario: 1. Presentación; 2. La negociación centro-región: el caso de la provincia de Valdivia; 3. Los actores: una mirada a sus posiciones en el conflicto; 4. Conclusiones del estudio.

SUMMARY: 1 . Introduction; 2 . The center-region negotiation: the case of the Valdivia province; 3 . The actors: a look at their standing in the conflict; 4. Conclusions.

PALABRAS ClAVES: gobierno regional; gobierno central; descentralización; Los Lagos; Chile.

KEY WORDS: regional government; central government; decentralization; Los Lagos; Chile

A partir de la década de los 1990, la descentralización política-administrativa de Chile se ha profundizado en forma gradual. Ello se ha expresado, entre otros aspectos, en la creación de gobiernos regionales y en la disposición política del gobierno central de dejar en manos de estas instancias el manejo de recursos para la inversión regional. No obstante, la reconfiguración de la actual división de las regiones no se ha tomado como un tema prioritario dentro de la política descentralizadora en cuestión. Sin embargo, ello no ha implicado que se esté obviando el tema por completo;

\footnotetext{
* Artigo recebido em mar. e aceito em dez. 2006. El autor agradece los comentarios de este artículo a los siguientes académicos Sergio Spoerer H.; Gabriela Rubilar D. y Tomás Moulian E. Este artículo fue realizado con los aportes de la beca de postgrado magíster de la Comisión Nacional de Ciencia y Tecnología (Conicyt). Concurso Regular 2001.

** Administrador público de la Universidad de Los Lagos, magíster en gobierno y gestión pública de la Universidad de Chile. Actualmente se desempeña como profesor asistente del Departamento de Gobierno y Gestión Pública del Instituto de Asuntos Públicos de la Universidad de Chile, dirige el Programa de Investigación y Desarrollo en Gobierno Regional y Local. Imparte la Cátedra de Gobierno y Administración Regional en la Escuela de Gobierno y Gestión Pública de la misma universidad. Dirección: Santa Lucia, 240 - Santiago Centro, Santiago, Chile. E-mail: pmonje@uchile.cl.
} 
ya que a nivel extraoficial, y de parte tanto del gobierno central como regional, se plantea la necesidad de hacer una propuesta de reestructuración de la división política-administrativa del país. Este estudio de caso fija su atención en las demandas de reestructuración recién mencionadas, haciendo especial hincapié en la observación del fenómeno de demanda por la regionalización de la provincia de Valdivia, en la décima región de Los Lagos, Chile, durante los años 1995/96. Dicho trabajo se realizó bajo la óptica de la negociación centro-región, con los objetivos de describir los componentes del proceso y de reconocer las condicionantes de las acciones de los actores en el mismo. Los resultados del estudio están vinculados al rol que ejercen los actores en el conflicto y negociación centro-región. Se consiguió realizar una caracterización de ellos, además de constatar la relación de clientela política que se produce entre la elite nacional y regional, como factor determinante en el resultado de la negociación. De la misma manera, se comprobó que el diseño institucional del sistema político induce este tipo de vínculo entre las elites mencionadas. Finalmente, el estudio presenta una serie de recomendaciones para el fortalecimiento de la política pública de descentralización de Chile, que están en marco de aminorar los efectos culturales del diseño institucional del país, tanto al interior de las elites nacionales como regionales.

Central-Regional negotiation in Chile: reality or myth - The case of the Los Lagos region

Since the 1990s, political-administrative decentralization has gradually intensified in Chile. It has expressed itself through the creation of regional governments and the central government's political will to delegate to these instances the management of funds for regional application, among other aspects. Even though the reconfiguration of the current regional division has not been considered a priority within this decentralization policy, this issue has not been completely overlooked. Extra-officially, as well as on the regional and central governments' level, the need for a plan that redesigns the country's political-administrative division has been recognized. This case study focuses on these demands for restructuring, especially on the demand for the regionalization of the Valdivia province, in the 10th region of Los Lagos, Chile, during 1995/96. The study adopted the central-regional negotiation perspective, so as to describe the process' components as well as the factors determining the actions of those involved. The results are tied to the role of the actors in the centralregional conflict and negotiation. It was possible to establish their characterization and to identify a political clientelistic relationship between the regional and national elites as a determining factor in the negotiation's outcome. It was also proven that the institutional design of the political system induces this kind of tie between those elites. Finally, the study 
proposes several measures to strengthen Chile's decentralization policy, in order to lessen the cultural effects of the country's institutional design, within both regional and national elites.

\section{Presentación}

Durante los años 1995/96 la comunidad valdiviana se creó grandes expectativas en torno al tema de avanzar en la regionalización de su provincia. El contexto era el siguiente: ya había pasado un gobierno elegido democráticamente que les sugirió postergar la demanda hasta una mejor oportunidad política. Sin embargo, el escenario había cambiado, comenzaba un segundo período democrático y se daban mejores condiciones; existían compromisos por cumplir para iniciar un proceso de negociación con el centro político del país.

Como coyuntura positiva, se daba que el presidente del Senado, Gabriel Valdés S., era representante de la provincia y su tienda política — la Democracia Cristiana - era la misma que la del presidente de la República. Existía cohesión social con respecto a la demanda, tenía el apoyo necesario para ser escuchado en Santiago. Se buscó y se le otorgó el apoyo por parte de las colectividades políticas a nivel nacional, además de realizar una abierta gestión de "lobby" ante todas las instancias de gobierno. Así se logró la validación técnica de la demanda; se estudió la factibilidad de ser región y se concluyó finalmente que Valdivia, en la práctica, era una región real.

Ante este brillante panorama, surgen diversas interrogantes: ¿qué paso?, ¿por qué las iniciativas y esfuerzos de validación de la demanda no produjo la regionalización de Valdivia?, ¿cuáles fueron los obstáculos?, ¿qué rol tuvieron los actores en el proceso de negociación? y ¿cómo influyeron estos en los resultados de la misma?.

En el transcurso del texto, se intentará responder todas las interrogantes planteadas con la mayor objetividad posible. El análisis posee un doble objetivo; por una parte, describir los componentes del proceso negociación centroregión que se dieron en este caso, y por otra, ver cuales son las condicionantes que determinan la acción de los actores en el mismo.

Resulta importante evidenciar al inicio del estudio, algunas limitaciones del análisis que se realiza a continuación, para que el lector no se haga falsas expectativas de lo que puede encontrar en el texto. En primer lugar, hay que tener presente que existe un proceso histórico - dado por más de 50 años (1925 a 1978) — que juega un rol preponderante en el caso. El hecho que la provincia de Valdivia fuese la capital político-administrativa de la macro región 
sur de Los Lagos, genera cierto nivel de condicionamientos de naturaleza subjetiva, que se deben tener presente y que se van construyendo con los despojos de servicios administrativos que culturalmente le parecían propios.

En segundo lugar, si bien el conflicto y la negociación son fenómenos diferentes, uno depende del otro. El conflicto es el fenómeno en el cual un sujeto demanda al otro por un evento determinado, sea este material o inmaterial. Y la negociación es aquella acción en la cual estos sujetos tratan de satisfacer sus demandas; siempre claro, bajo la lógica de tener los menores costos posibles.

En tercer lugar, se observarán los hechos desde la perspectiva de los actores. Entre los cuales se incluye a representantes sociales, de gobierno, parlamentarios, miembros de partidos políticos y técnicos.

Presentado el estudio de caso en su dimensión de texto, quisiéramos entregar algunos elementos estructurales de un proceso de negociación (Curle, 1978; Lederach, 1985; Dana, 1992; Fisher y Ury, 1991; Ury, 1994, con el fin de hacer un pequeño marco referencial introductorio de la investigación. Estos componentes responden a tres interrogantes básicas: ¿quiénes negocian?, ¿qué negocian? y ¿cómo negocian?.

¿Quiénes negocian? Esta pregunta nos remite al problema de constitución de los actores de negociación y a la posibilidad de superar las contradicciones internas de ellos. Para los casos de confrontación entre gobierno central y sociedad regional - en concreto con el Comité Nueva Región — la negociación entregó:

- espacio para posibilitar una negociación horizontal y subterránea al interior de los miembros del comité y de la sociedad valdiviana; en otras palabras, que se pudieran poner de acuerdo los representantes de posiciones más radicales con los actores políticos más moderados. Ello permitió establecer una salida política, donde los negociadores debieron representar a todos los sectores, además de demostrar autoridad moral y política frente a sus bases;

、 en otro ámbito, la negociación también debe permitir un espacio para el gobierno, con el fin de que éste ayude a resolver las tensiones del conflicto. Por ende, resulta necesario además de dicho espacio, dinámicas políticas pertinentes para que todos los actores puedan superar las resistencias a un posible acuerdo, en especial la de los sectores más radicales. Por otra parte, es importante poder concentrar los intereses globales que orientan las políticas macrosociales, de forma tal, que su orientación no contradiga lo que puede 
ser un acuerdo integral. Esto plantea la necesidad de actores que tengan clara la acción de negociación — tanto por parte de los valdivianos como del gobierno - para garantizar una plena representatividad social y política.

¿Qué negociar? Si bien la respuesta correcta es: a las incompatibilidades o problemas de fondo, eso no siempre resulta claro. Lo sustancial se da por las posiciones que asumen los actores tanto al interior de la negociación, como fuera de ella. Y por eso es necesario develar los intereses de fondo que tiene cada parte y cómo estos actúan frente al conflicto. En este sentido, hay que aclarar el origen, la estructura y la magnitud del problema para posibilitar los caminos de solución. Por último, la negociación debe permitir y facilitar el tratamiento de otros puntos que van a ser adyacentes al proceso, para así plantear el cambio de realidad a otros sectores del país que son observantes del mismo.

¿Cómo negociar? - o en otras palabras - ¿cómo generar alternativas diversas y variadas, que puedan dar una respuesta satisfactoria a los múltiples intereses en juego?

Siempre en una negociación existe la necesidad de generar soluciones distintas; y en este sentido, es importante la participación de actores que tengan alternativas de solución y que no estén limitados a un solo resultado. Por otro lado, también se requiere en términos de procedimiento, una negociación que permita la resolución de acuerdos parciales que apunten a la dinámica. Y a la vez, que garanticen que ésta continúe sin interrupción al mismo tiempo en que se van disminuyendo los niveles de conflictividad del proceso.

\section{La negociación centro-región: el caso de la provincia de Valdivia}

Este artículo tiene como objetivo entregar la información necesaria para integrarse de plano al estudio de caso titulado "La negociación centro-región en Chile: realidad o mito - el caso de la región de Los Lagos". El estudio analiza el conflicto regional que presentó la provincia de Valdivia, durante los años 1995/96, sobre la demanda de regionalidad de la misma. Y si bien ésta es una petición histórica de la comunidad valdiviana, durante los años citados tomó mayor fuerza, tanto por la acción de distintos actores institucionales, como por la de personas de alto nivel de influencia en el gobierno nacional. Ese es el caso del entonces presidente del Senado, Gabriel Valdés, quien a la vez era senador por la zona.

Se debe dejar claro que si bien Valdivia no logro ser región, sí acepto realizar una serie de acciones con la cual ha demostrado que su elite política, 
económica e intelectual ha sido capaz de plantearse un plan de desarrollo para la provincia y probar su capacidad de conducción y liderazgo en su propio futuro.

Por otro lado, la relación dominante entre Valdivia y el centro político es de carácter clientelista, causada por una crisis permanente de relaciones de poder asimétricas centro-región. Éstas se han mantenido por medio de negociaciones de proyectos, que confluyen en una agenda programática de desarrollo territorial, tendientes a superar la situación que ha sido producto de las acciones y protestas de las elites locales.

Cada vez resulta más necesario saber de estos conflictos, debido a que en el diagnóstico general, la descentralización es un proceso que no es inmutable en el tiempo; está muy vinculado a las capacidades de las personas y de las de sus organizaciones, quienes muchas veces demandan mayor participación y acción en la construcción de su propio desarrollo. Si se observa desde el punto de vista de una democracia participativa, la tendencia central más fuerte es dar poder a los ciudadanos; pero para que esto ocurra, es importante generar acuerdos negociados que entreguen instrumentos y acciones necesarias para realizar el traspaso de competencias del nivel central al regional.

Por último, cabe destacar que la validez de este estudio recae en el contexto actual de Chile, al considerar recientes informaciones de prensa que señalan que el actual gobierno manda a tramite legislativo una nueva ley sobre regionalización, que tiene como meta, lograr la facultad de crear nuevas regiones. Por ende, si se tomara en cuenta la experiencia valdiviana, sería posible diseñar un proceso de construcción de plataformas regionales que permitan evaluar la factibilidad real de ser regiones quienes lo pretendan. Bajo este punto de vista, lo que ha realizado Valdivia en forma muy instintiva y espontánea, resulta necesario analizarlo y sistematizarlo con el fin de plantear un aporte certero al futuro proceso de reorganización regional del país.

\section{Valdivia nueva región como conflicto de estudio}

El conflicto sobre regionalidad de la provincia de Valdivia data desde la década del 1970, cuando la dictadura militar realiza la regionalización del país, promovida por una concepción longitudinal del territorio que lleva a cabo la reforma política-administrativa, que es respaldada por una visión geopolítica y económica diferente de percibir a Chile hasta esa época. Esta visión está vinculada a una concepción de seguridad nacional del territorio y además a un fortalecimiento de la explotación de recursos naturales, con el objetivo de ampliar la oferta de productos exportables no tradicionales al mercado inter- 
nacional. Lo cual, se asienta en una nueva base productiva nacional territorial, que deja a Valdivia fuera de los nuevos paradigmas de desarrollo del país.

Este conflicto tiene distintos puntos críticos o de movilización social, que partieron - en una primera instancia - durante la dictadura militar. En este período, la elite provincial expresó sus demandas sin mayor apoyo político por parte del entonces presidente de la República. Luego, la segunda etapa del conflicto se remonta a la década de los 1990, durante el gobierno de Eduardo Frei Ruiz-Tagle, donde los distintos actores políticos, económicos, sociales y culturales tuvieron la fuerza necesaria para poner en debate nacional-regional la demanda de la nueva región de Valdivia.

Lo anterior se dio entre los años 1995/96, teniendo como resultado la negociación entre el centro político y la provincia. Dichas conversaciones se realizaron bajo el marco de recomendaciones dadas por expertos contratados, para el estudio de factibilidad de que Valdivia fuese una nueva región. En términos reales, si bien esta negociación tuvo como resultado el aplazamiento de la regionalización de la zona tratada, logró que se articulara un nuevo fenómeno que reconoce de hecho a la región de Valdivia; esto, gracias a las razones y argumentos tanto de los valdivianos, como de los expertos encargados del estudio. Así se dio paso a la creación de una Agenda Pactada, entre el sector público y privado de la provincia, para fortalecer los criterios distintos de desarrollo que tiene dicho sector con el resto de la región de Los Lagos, sobre todo de su parte sur-austral. Además, el gobierno central entregó mayores atribuciones a la gobernación provincial con el fin de llevar a cabo los compromisos públicos que se adquirieron en la agenda.

La tercera etapa es la ejecución entre los sectores que intervienen en la construcción de la Agenda Pactada de Desarrollo. Los objetivos centrales de esta agenda son:

- dar una señal esperanzadora de la decisión de los sectores público y privado para enfrentar de manera renovada y pactada los problemas que han impedido o frenado el desarrollo provincial;

impulsar una mayor capacidad de interlocución de los principales actores de desarrollo provincial, para que se integren coordinada y propositivamente a las tareas que definen y condicionan el futuro de la provincia;

v construir en el marco de los postulados nacionales y regionales de desarrollo, una propuesta colectiva que refleje el acuerdo provincial en torno al "proyecto futuro" y a sus prioridades;

- acordar un plan de trabajo entre el sector público y privado, que explicite compromisos coordinados y focalizados para materializar programas y proyectos prioritarios; 
\ fortalecer la capacidad del gobierno para negociar a nivel regional y nacional las decisiones e instrumentos necesarios, para impulsar el desarrollo de la provincia de Valdivia;

v iniciar un esfuerzo de gestión moderna y descentralizada a partir de un marco programático y operativo, acordado entre los principales actores sociales y económicos de la provincia;

v potenciar la malla social de la provincia de Valdivia y su imagen corporativa, para asumir tareas y compromisos conducentes a su propio desarrollo y lograr - colateralmente - fortalecer su capacidad de autogestión. Evaluación que se encuentra en pleno proceso desarrollo.

Por último, se podría hablar de una cuarta etapa que aún no se ha iniciado y que depende de las señales que dé el gobierno con respecto a las reformas institucionales necesarias para llevar a cabo un nuevo proceso de regionalización del país, en el cual la demanda valdiviana vuelva a tener la posibilidad de lograrse. De hecho, por informaciones periodísticas recientes, se estaría dando la posibilidad de que se concreten estas reformas con el proyecto de ley propuesto por el gobierno al Congreso, que busca como objetivo replantear la estructura política-administrativa del país. Con esto último, se rearticularía el conflicto valdiviano con una base distinta a las etapas anteriores, ya que se adicionan mejores argumentos y hechos que permiten legitimar y lograr una propuesta más firme para establecerse como una región real.

En esta primera lectura del conflicto y de su negociación se utilizará como texto base el documento elaborado por los consultores Boisier, Dockendorff y Marinovic (1996). Este informe abordó de manera específica las demandas de la provincia de Valdivia por conformar una nueva región y formó parte del estudio encargado por la Subsecretaría de Desarrollo Regional y Administrativo del Ministerio del Interior.

Cabe destacar que este documento es de carácter confidencial para la época y representa - en cierta forma - la carta de navegación que tuvo el gobierno para la resolución del conflicto, ya que presenta un diagnóstico de la situación y algunas proposiciones para manejar el problema por medio de los mecanismos y elementos de negociación con que se podía contar a la fecha para la resolución del mismo, por parte de la institución recién citada.

En el presente artículo se entregan los principales aspectos históricos, políticos, económicos y socio-culturales que fundamentan la demanda valdiviana con un enfoque de carácter sistémico, que aborda los aspectos mencionados como parte del sistema regional que se construye a nivel de la provincia. 
Desde el punto de vista histórico, se plantea que la provincia de Valdivia conforma, junto con Osorno, Llanquihue, Chiloé y Palena — que también poseen el mismo rango - , la actual región de Los Lagos, décima región. Sin embargo, en la primera regionalización ${ }^{1}$ del país, que se estableció durante el gobierno del presidente Frei Montalva, la provincia de Valdivia integró, junto a las provincias de Cautín y Osorno, la inicial región de Los Lagos.

Desde fines de los 1970 y hasta la promulgación en 1974 de la actual regionalización, ${ }^{2}$ la provincia de Valdivia formó parte de una región bi-provincial junto con Osorno.

${ }^{1}$ Según Sthor (1969), los criterios de la regionalización realizada en 1967 fueron los siguientes.

a) Sistema nacional de regiones: debía establecerse un sistema coherente de regiones que cubriera todo el territorio nacional, sin que se produjeran brechas ni superposiciones.

b) Factibilidad para fines de programación y administración del desarrollo: esto se refiere principalmente al número y tamaño de las regiones. La oficina de planificación regional originalmente recomendó diez regiones para aumentar la eficiencia de la planificación y administración regional.

c) Divisiones administrativas: un criterio determinado, basado en razones políticas y administrativas, que estableció que se respetaran las fronteras provinciales existentes. Esto estableció que las provincias no podían dividirse entre regiones. El objetivo era mantener la integridad de las provincias.

d) Existencia de al menos un polo de crecimiento: un concepto básico de la política regional en Chile era el intento de activar las regiones mediante una inversión concentrada en los polos de crecimiento.

e) Complementación socio-económica: debido a que las regiones debían constituir unidades con cierta autonomía económica y administrativa, también necesitaban contar con la posibilidad de complementaciones internas. Esto se refiere a una cierta complementación entre el producto y el consumo regional, entre los recursos naturales y los urbanos (humanos y de capital), y entre las áreas más avanzadas y la más atrasadas dentro de la propia región.

f) Economías de escala regionales: con el objeto de crear un auto-crecimiento y un mayor grado de substitutos regionales de las importaciones, dentro de un marco de una comparativa ventaja nacional, las regiones debían contar con mercados internos de tamaño suficientemente grande como para poder ofrecer economías de escala a las industrias regionales.

${ }^{2}$ Según la Comisión Nacional de la Reforma Administrativa (Conara, 1976) los nuevos criterios de regionalización fueron:

a) cada unidad regional debería contar con una dotación de recursos naturales que avalara una perspectiva de desarrollo económico de amplia base, compatible con el ritmo de crecimiento que desea imprimir el país;

b) debía poseer una estructura urbano-rural que garantizara un nivel de servicios básicos a la población regional y además, contar con un lugar central que actuara como núcleo de las actividades económicas y sociales para orientar la dinámica de crecimiento;

c) es necesario - y hasta imprescindible - que exista una base poblacional capaz de impulsar el desarrollo, actuando como fuerza de trabajo y mercado de consumo; 
En ambos casos, la ciudad de Valdivia fue definida como capital regional, constituyéndose así en la cabeza de un sistema territorial. El cual, estaba configurado a través de un concepto de región, que privilegiaba - además de los criterios de identidad cultural y de los de una red básica de relaciones funcionales urbano-rurales - una dimensión económica espacial y una base de recursos, visualizada con criterios de diversificación productiva, que aseguraba — desde el punto de vista económico — una integración con notorios grados de autosuficiencia en su dinámica de crecimiento.

La ruptura en 1968 de la gran región compuesta por las provincias de Temuco, Valdivia y Osorno - dejando a la primera como región independiente y a Valdivia y Osorno conformando la región de Los Lagos —, no cambia sustancialmente el concepto estratégico, la visión geopolítica del momento, ni la manera en que se visualiza a fines de los años 1960 la inserción nacional e internacional de estas provincias bajo una perspectiva a largo plazo.

Sin embargo, la regionalización de 1974 se realiza en un marco referencial absolutamente distinto, donde - según la terminología usada en el presente artículo - se produce un cambio dramático en los escenarios contextual, estratégico y político, que definen la modalidad del desarrollo regional. El país prioriza otros aspectos y ello significa, en el caso de la provincia de Valdivia, la perdida de su rol privilegiado que desempeñaba en el pasado. A raíz del golpe de Estado de 1973 la situación socio-política y económica de la nación, se caracteriza por tener un clima de conflicto interno y de consolidación de un gobierno de facto. Obviamente, esta situación determina también una forma diferente de visualizar las perspectivas de integración con los países vecinos y las modalidades de inserción del país en la economía internacional.

Según la opinión de ciertos consultores, la décima región creada en 1974 - hoy vigente - , es la expresión de un diseño territorial que maximiza el logro de objetivos de seguridad nacional y de carácter geopolítico, privilegiando la consolidación política-administrativa y la conducción centralizada de los gobiernos regionales, así como también, la atención preferente a las relaciones

d) además es indispensable que su delimitación geográfica contemple los objetivos de la seguridad nacional en armonía con las metas de desarrollo regional y el manejo de recursos;

e) el tamaño de las regiones debe ser tal, que facilite la eficiencia desde el punto de vista de la administración territorial y del manejo de recursos;

f) estos criterios técnicos deben también acompañarse con un conjunto de medidas y normas que permitan su adecuada administración y gobierno;

g) en cada región se establece una nueva institucionalidad homogénea y equivalente, basada en el principio de desconcentración del poder y la descentralización administrativa, debidamente integrada al sistema de planificación y al proceso de toma de decisiones. 
longitudinales de Chile. Esto incluye la proyección hacia el país austral, a partir de Puerto Montt, por sobre una integración fronteriza necesariamente postergada hasta resolver situaciones delicadas de orden político y limítrofe, propias del escenario contextual de aquel momento.

La nueva región - así concebida - integra las provincias de Valdivia, Osorno, Llanquihue, Chiloé y Palena, destacando a Puerto Montt como capital regional de un territorio clave para asegurar el logro de los objetivos estratégicos de carácter geopolítico de seguridad nacional. En este diseño se relega a Valdivia a un segundo plano, condición y actuación radicalmente distinta a la que desempeñara en las regionalizaciones anteriores. Este cambio tan radical - con notables diferencias en las funciones asignadas a Valdivia frente a su rol histórico - incuba resistencias que afloran, tanto en el marco referencial surgido en 1974, como al renacer las dinámicas de desarrollo y crecimiento anunciadas a fines de la década de los 1960. Y si bien éstas aún persisten, ahora reaparecen mejor perfiladas debido al nuevo escenario en que hoy se inscribe Chile y la región.

Desde el punto de vista de los consultores, existen indicadores de distinta naturaleza que revalorizan a Valdivia en su calidad de región real. Se pondera de manera diferente los criterios de seguridad nacional en el ámbito del proceso democrático, y la disminución de las tensiones limítrofes posibilita esquemas de desarrollo integrado a escala nacional e internacional, con perspectivas de internacionalización conjunta de la economía del cono sur. Por otra parte, la expresión legítima de los intereses locales a través de mecanismos de participación, posibilita la discusión de los intereses de provincias específicas.

En estas condiciones, y a partir de 1990, se han desarrollado propuestas desde Valdivia, que plantean una demanda para obtener el status de región político-administrativa.

A partir del establecimiento de la actual configuración regional, la ciudad de Valdivia perdió la capitalidad regional a favor de la ciudad de Puerto Montt. Situación, que al ser considerada en forma muy negativa por parte de la población, ha motivado la activación de una demanda típicamente regionalista: obtener el status de región.

Esta petición demostró - o demuestra - una creciente capacidad para aglutinar a diversos sectores de la sociedad civil de la provincia, al punto de que existió - o existe - una suerte de "comité cívico" que opera con el lema: "Valdivia Nueva Región". La demanda fue acogida — o es acogida — en el ámbito político-parlamentario y contó con el apoyo explícito del entonces presidente del Senado, Gabriel Valdés S., y con el de otros parlamentarios, cuyas circunscripciones electorales están contenidas en el territorio regional. 
De manera adicional se sumaron — según los consultores — interesados de distintas naturalezas, que sin postular la segregación territorial de Valdivia, estuvieron - o están - dispuestos a apoyar decisiones que valoricen aquella supuesta condición de región real, siempre que esto no implique cambios en los límites regionales.

Cabe destacar sin embargo, que así como hay fuerzas ${ }^{3}$ que postulan una revisión constructiva del sistema regional chileno y una evaluación de casos tan legítimos como el de Valdivia, también hay quienes ${ }^{4}$ ven en estas instancias peligrosas aperturas que podrían posibilitar el cuestionamiento de elementos consustanciales al modelo político-económico global y a su expresión territorial, regionalización sancionada por la Constitución de 1980.

El gobierno - según los consultores - tiene tres opciones, que no son del todo independientes, para enfrentar la situación planteada por la demanda de los valdivianos. Son puntos que representan maneras diferentes de entender la situación de fondo que subyace en estas peticiones; además de estimar una valorización distinta de costos-beneficios. Las posibilidades serían las siguientes:

v no innovar en la situación actual, manteniendo el status existente y asumiendo que el problema no tiene la importancia pretendida y/o que los costos de enfrentarlo son demasiado altos para la política regional oficial del gobierno. Se mantiene e impone entonces, la realidad vigente;

v establecer un proceso de negociación con los actores fundamentales y construir soluciones modernas e innovadoras, que respetando la región actual, posibiliten que Valdivia alcance parte importante de sus aspiraciones regionalistas;

v revisar la regionalización y crear de inmediato - y con todos los instrumentos disponibles en la política de descentralización - una nueva región en torno a Valdivia, segregándola de la actual décima región y asumiendo los postulados de los regionalistas valdivianos.

A juicio de los consultores, la primera opción resulta difícil de aceptar política y técnicamente, de acuerdo a los postulados de los gobiernos de la

\footnotetext{
${ }^{3}$ Entre los que encontramos, Corchile, Corbiobio entre otras, así como también grupos organizados que proponen la federalización de Chile, llamados los federalistas.

${ }^{4}$ Grupos de regiones que han sido beneficiados del centralismo regional, por haber sido nominadas capitales regionales y que han manifestado su opinión en contra de un proceso de reestructuración regional y la derecha política que piensa que la obra histórica institucional del gobierno militar no debe ser reformada, lo que incluye el proceso de regionalización.
} 
concertación. Esto, aún cuando el planteamiento tiene muchos defensores que entienden que el enfrentamiento de los problemas regionales debe realizarse en el ámbito decisional de cada región en particular, sin la necesidad de una política regional a escala nacional y/o a una imagen predefinida de un ordenamiento territorial deseado. Las regiones así concebidas, conforman un sistema regional espontáneo sancionado por la Constitución de 1980 y que en su desarrollo desequilibrado y residual, han sido funcionales al éxito del modelo macroeconómico que viene impulsando el país.

Documentos oficiales sostienen que sólo deberá haber intervenciones regionales del gobierno central y orientaciones de política de desarrollo a nivel territorial, cuando existan problemas de gran repercusión política a escala nacional o por razones de carácter moral, dado efectos de extrema gravedad que la política de libre mercado pudiera tener sobre grupos de población, medio ambiente o regiones específicas. Se desconoce, de esta forma, la necesidad imperiosa de acompañar creativamente la materialización del escenario territorial del futuro, con el fin de lograr beneficios tanto políticos y socioeconómicos del país, como para los postulados del gobierno nacional.

Por tanto, los escenarios futuros que condicionan el avance del país, exigen políticas regionales de nivel nacional que posibiliten los indispensables desarrollos descentralizados y participativos, en ámbitos territoriales con ventajas comparativas y competitivas, acordes con las exigencias de una economía globalizada y a la configuración de un sistema territorial concordante a los postulados de mayor equidad, sostenibilidad y sustentabilidad.

Para los consultores, el caso de Valdivia debe ser resuelto asumiendo el enfrentamiento de soluciones que permitan construir el futuro en el marco de lo previsible, poniendo la política regional al nivel de los instrumentos que son indispensables para concretar los objetivos del país en su conjunto. Ello, materializando los escenarios territoriales compatibles con las dinámicas nacionales postuladas. Es una exigencia ineludible el poner la política regional en el escenario perspectivo del país y no dejarla sólo como respuesta a los problemas que van surgiendo desde las distintas regiones, recibiendo así, tratamientos ineficientes e inoportunos. Resulta esencial, por ende, conducir de forma armónica una política global regional, asegurando su coherencia y compatibilidad con componentes especialmente complejos de la dirección política y económica nacional. En definitiva, posibilitar el logro de los ambiciosos objetivos territoriales en beneficio de cada región en particular y del sistema nacional-regional en su conjunto.

La segunda opción plantea un proceso de negociación entre el gobierno y la comunidad valdiviana, que consiste en desplazar la demanda desde el plano formal al plano de lo sustantivo; es decir, centrar la dinámica social de 
los valdivianos en el desarrollo de la provincia de Valdivia y no en la mera demarcación regional. Se trata, en otras palabras, de pasar del "contenedor al contenido". Y no es que la "capitalidad" o la "regionalidad" — expresado en un lenguaje simple - carezca por completo de importancia, pero ciertamente, ella configura un factor menor de desarrollo, si se compara con otros aspectos que no están relacionados con el status provincial o regional.

El resultado principal en todo proceso de negociación es el conocimiento científico de aquello que constituye el asunto a negociar. La racionalidad y conocimiento del caso - por ende - de todos los actores involucrados, legítima la negociación y sobre todo, hace aceptables sus resultados.

El concepto mismo de región está hoy en día sometido a una profunda revisión, como resultado - en parte — de las nuevas condiciones creadas por la revolución científica y tecnológica. Y no menos profunda es la revisión que marcha en torno al concepto de desarrollo regional.

Por otra parte, hay que prevenir a todos los interesados en la regionalidad de Valdivia, que no se descarta la posibilidad de obtener una victoria pírrica (aunque de todas las opciones ésta se vislumbra difícil a corto plazo), donde la energía social se podría estar empleando a favor de una causa factible de tornarse rápidamente obsoleta, en vez de ser canalizada en la dirección correcta.

Sin embargo, también se debe tener presente que aún son válidos algunos criterios geopolíticos que determinaron la creación de la décima región y que al avecinarse la definición de los diferendos limítrofes finales con Argentina, hacen inviable cuestionar ahora la vigencia de la delimitación regional. Situación que puede hacer fracasar la posibilidad de que Valdivia se configure como una región política-administrativa a mediano plazo.

En relación a la tercera opción, la transformación de la provincia en región, hay que recordar que la configuración de territorios en 1974 estuvo determinada por una concepción físico-funcional y geopolítica, cuya matriz territorial es la provincia o la micro región (expresión abandonada posteriormente por el legislador). Así, una región puede estar constituida por provincias. Este criterio excluye naturalmente una estructura territorial flexible, que considere a provincias individuales, a ciudades de gran tamaño - como es el caso de Alemania - o bien, a grupos de comunas en la configuración de regiones.

La creación de regiones supone entonces, en primer lugar, definir los criterios a considerar para cada nueva estructura. Según la opinión de los consultores, el criterio principalmente físico-funcional-geopolítico aplicado en 1974, adolece de severas limitaciones, dentro de las cuales cabe citar: un diseño centralizado y voluntarista y una naturaleza deductivista, definidora de una matriz territorial estándar (región — provincia — comuna). Mantener los criterios recién nombrados, obligaría a realizar una compleja operación 
de reforma territorial que tendría efectos sobre la actual estructura de las regiones de la Araucanía y de Los Lagos, y sobre la radicación del gobierno en Puerto Montt.

En cualquier caso, los pasos jurídicos para la creación de regiones son tres:

v reforma a la Constitución política dado que el artículo 45, inciso uno, fija el número de regiones en 13. Esta modificación a la Constitución, de acuerdo al artículo 116, puede tramitarse por mensaje presidencial o por moción de cualquiera de los miembros del Parlamento, con sólo la condición que los patrocinantes no excedan el número de 10 diputados o cinco senadores respectivamente. La aprobación de tal tipo de reforma exige los tres quintos de los diputados y senadores en ejercicio;

v una vez aprobada la reforma de la Constitución se debe proceder a determinar la estructura provincial y/o la delimitación intrarreginal de la o las regiones a ser afectada(s) por dicha configuración, sobre lo cual se deberán aprobar los proyectos de ley correspondiente a cada caso, y la capital cabecera de la región, lo cual es materia de una ley de quórum calificado, a iniciativa exclusiva del presidente de la República;

v la instalación de la institucionalidad regional requerirá por último de normas específicas para dotarla de recursos: humanos (plantas de personal); financieros (presupuesto) y materiales (infraestructura y equipamiento del gobierno). Todo lo cual es - como en el paso anterior - de iniciativa exclusiva del presidente de la República.

La creación de una nueva región en Valdivia presupone, además, aceptar diversas implicancias. Por ejemplo, de carácter político (posible "efecto en cadena", duras negociaciones gobierno/oposición, modificación a la Ley Orgánica Electoral y composición del parlamento, entre otras); de tipo territorial (alteración del ordenamiento territorial establecido en Chile, independiente a las críticas que se pueden generar por tal reestructuración); de tipo económicopresupuestario, e inclusive, de tipo sociocultural. Finalmente, el sistema nacional de generación de datos de base territorial se vería seriamente afectado.

A partir del análisis de la situación de Valdivia — realizada por los consultores ya mencionados - y las propuestas de acción que ellos mismos plantearon para resolver el conflicto, se está en condiciones de abordar el caso de negociación centro-región, ya habiendo entendido - desde el punto de vista histórico y teórico - el fenómeno de la descentralización en Chile.

El estudio de caso observará los resultados de la demanda realizada por la comunidad de Valdivia, en su contexto político, económico, administrativo y cultural-social, a través del análisis de informaciones periodísticas, que muestran 
una síntesis histórica del conflicto y la opinión de los principales actores de distintos ámbitos del que hacer valdiviano.

\section{Los actores: una mirada a sus posiciones en el conflicto}

Este acápite tiene por objeto develar y analizar las acciones y posiciones asumidas por cada uno de los actores relevantes en el conflicto, como también las opiniones de representantes de la comunidad organizada.

El propósito de lo anterior es porque la evidencia empírica - es decir, la enunciación de discursos lingüísticos de los actores locales, regionales y nacionales, a través de los medios de comunicación de masas - muestra en una instancia primera, sus posiciones frente al conflicto.

Teniendo en cuenta lo anterior, se debe realizar luego una depuración de esta evidencia, con el fin de encontrar el carácter evidencial de cada una de las posiciones. Para ello se intentará realizar una reconstrucción del sentido de los discursos bajo una situación micro y macro social de enunciación. Análisis que estará guiado por la articulación simbólica de códigos que responden a la construcción de un proceso social; en este caso, el conflicto de regionalidad de la provincia Valdivia.

Para lo anterior, los modelos de representación y comprensión de las retóricas discursivas en un contexto social y en un momento histórico - como es el estudiado - sirve para reconstruir los intereses de los actores que están implicados en el conflicto.

Para realizar esta etapa del estudio, se han identificado y clasificado a los actores en distintos niveles que se definen por su procedencia territorial y posición decisional de las distintas estructuras organizacionales a las que pertenecen, sean éstas políticas, administrativas, sociales y/o económicas. La clasificación se divide de la siguiente manera: actores locales, provinciales, regionales y finalmente, actores nacionales. ${ }^{5}$

$\mathrm{El}$ análisis se realizará en base a las opiniones vertidas en la prensa escrita de cada uno de los personajes mencionados, durante el período del conflicto (1995/96). Se considerarán en el análisis los mensajes, que además de resultar los más importantes, muestren los juicios necesarios para reconstruir las estrategias negociadoras y las actitudes frente a la demanda.

\footnotetext{
${ }^{5}$ Ver anexo 1, esta clasificación es sólo un instrumento para ordenar, a partir del análisis de sus opiniones se utilizarán otros criterios de ordenamiento.
} 
Para estudiar las opiniones de los actores se decidió utilizar el método de análisis estructural propuesto por Jules Gritti, ${ }^{6}$ que contempla la aplicación de seis filtrajes sucesivos de la información, ordenados de acuerdo a los siguientes niveles: nivel de contenido, nivel de enunciado y nivel de relación de comunicación entre locutor y público.

Para el desarrollo de este estudio, se optó por trabajar esencialmente en el primer nivel de análisis, dado que éste enfatiza los contenidos y permite describir las oposiciones y las asociaciones de cada actor. Los contenidos de estas dos últimas dimensiones resultan centrales para responder a los objetivos de este trabajo y por lo mismo, han sido relevadas como categorías de análisis. ${ }^{7}$

Estes procesos de filtraje, que en esta ocasión ser realizará con las dimensiones de oposición y asociación, están orientados a hacer emerger estructuras distintas a las propias del ámbito retórico, es decir, buscan identificar fenómenos que estén más allá de la estructura tradicional de despliegue de un texto. Gritti habla de identificar la "estructura latente por sobre lo manifiesto a nivel retórico".

Este método asume que los actores desarrollan estrategias discursivas, en donde se busca encontrar un plus de significación que ellos dejan escapar involuntariamente y que este método pesquisa y analiza.

Si bien resulta un método útil para analizar cualquier tipo de texto/ discurso, se entiende que los procesos de filtraje descriptivo no dan cuenta de una verdad única dentro del texto. Ellas varían de acuerdo a las interpretaciones que se realicen y del contexto de la problemática planteada en el mismo.

En resumen, el método de Gritti postula la utilización de tres ópticas básicas de filtraje a desarrollar en forma sucesiva:

v una óptica estructural "dura";

- otra que responde a la relevancia del análisis textual (más cercana a los análisis literarios);

v y un tercer nivel de filtraje que proviene de la teoría de la comunicación, en una versión más simple.

Como se mencionó anteriormente, este estudio utilizará el filtraje a nivel de contenidos. Ello ha permitido agrupar a los actores en diferentes posiciones:

\footnotetext{
${ }^{6}$ Método estudiado en el curso: Metodología Cualitativa para el Análisis del Discurso Público, dictado por el profesor Fernando De Laire Ph.D., Semestre Otoño, marzo/julio 2001 en el Magíster de Gestión y Políticas Públicas.

${ }^{7}$ Ver la aplicación del método en el anexo 2.
} 
maximalistas, negociadores, obstaculizadores y facilitadores. Categorías que nacen a partir del análisis de sus planos discursivos, en donde afirman un rol o carácter sobre la demanda y las acciones que se han ido dando en el transcurso del conflicto. Metodológicamente, ésta ha sido desarrollada a partir de la información periodística recogida durante los años 1995/96, y posteriormente analizada por el método antes descrito, que se encuentra en el anexo 2 de este artículo. Por tanto, en esta parte están los resultados analíticos que se sustentan en la aplicación de la metodología desarrollada en el anexo.

\section{Los maximalistas}

Los maximalistas son aquellos actores que en su plano discursivo destacan claramente posiciones inflexibles. Defienden sus planteamientos a favor de la demanda y atacan fervientemente a otros personeros que se oponen o impiden el logro de lo requerido. El resultado esperado es que se logre la demanda tal como la han planteado, no se disponen a negociar ninguna parte de ella. Muchas veces estos actores en procesos de negociación son llamados los "duros". Y se percibe que sus planteamientos, reflexiones y acciones van dirigidos hacia su máxima posición razonable: lograr que Valdivia sea región.

\section{Raúl Basso, presidente del Comité Nueva Región}

Una de las temáticas centrales del estudio, es la percepción del conflicto y de las negociaciones entre los actores locales y los nacionales. En las opiniones del actor analizado se pueden destacar dos ejes argumentativos; por un lado, como se ha ido dilatando la solución del conflicto, debido a la falta de voluntad política de las autoridades nacionales y por otro, el reconocer los efectos negativos en el desarrollo de Valdivia por no ser región.

Raúl Basso devela su posición a través de los siguientes ejes temáticos: negociación; regionalización; voluntad política del gobierno; percepción de políticos y autoridades; y finalmente, la solución del conflicto.

En cada uno de los ejes mencionados se puede apreciar un polo positivo - o deseado - y un polo negativo - o no deseado - , tanto de manera explícita como implícita. Claramente se manifiesta su deseo por conseguir la regionalidad de Valdivia, y para ello plantea que existen argumentos más que suficientes para que la demanda a las autoridades y políticos se cumpla sin problema.

Basso denota una posición de carácter maximalista, dado que además de extremar los argumentos, su adjetivación así lo demuestra; cada proposición 
apunta directamente a potenciar la demanda. Por otro lado, a la vez que denomina a las autoridades de gobierno como "los otros" — refiriéndose a los opositores a la demanda que encabeza - emite hacia ellos juicios condenadores, ya sea utilizando el factor tiempo, como recurriendo a la identificación corporativa de instituciones como "la Comisión de Constitución del Senado". Cabe mencionar además, que da a conocer nombres de autoridades involucradas que entorpecen la gestión en curso; en este caso, el del entonces subsecretario de Desarrollo Regional y Administrativo del Ministerio del Interior, Marcelo Schilling.

A partir del análisis realizado es posible afirmar que su posición frente a una posible solución al conflicto es dura y taxativa, sólo el cumplimiento de la demanda resulta válido para él. En otras palabras, sólo existe la opción de que Valdivia sea región. Y ello, sigue expresando su carácter de actor maximalista dentro del asunto.

A través de sus discursos es posible establecer que este actor ha realizado una serie de asociaciones y equivalencias, tanto explícita como implícitamente, entre los términos utilizados. De hecho, se advierte que su posición como dirigente más importante del comité, hace que sus palabras estén dirigidas con el fin de generar una convicción plena en las personas que lo apoyan. Y en el caso de sus opositores o para quienes están contra su demanda, mantiene una posición clara e intransable.

Considera que la movilización permite ganar la comprensión por parte del presidente de la República y tiene la convicción que el conflicto debe ser solucionado por el centro político del país. Asimismo, manifiesta que no existe la voluntad política de detener el proceso de desburocratización de la provincia y anhela que Valdivia vuelva a ser un centro político administrativo importante para la provincia.

Cree que la solución no debe esperar más tiempo, que ya ha transcurrido el suficiente y que se requiere tomar una estrategia de sensibilización mucho más fuerte, sin tranzar la demanda de regionalidad de Valdivia. No le interesa generar una alternativa distinta de solución al conflicto, debido a que necesita crear cohesión de grupo para la convocatoria de una posible movilización anunciada. La cual, sería utilizada como factor de presión a las autoridades para resolver favorablemente la demanda de los valdivianos.

\section{Gustavo Serrano C., director del Diario Austral de Valdivia}

Gustavo Serrano tuvo posiciones de carácter maximalista. Y valiéndose de su condición de director del único diario de la provincia, mantuvo opiniones 
confrontacionales contra los representantes del gobierno y quienes manifestaran discrepancias con la voluntad de la demanda de los valdivianos.

Sus ejes argumentativos fueron los siguientes: regionalización, centralismo, negociación y la solución del conflicto. Cada uno de los cuales fue argumentado consistentemente por este actor, caracterizándose por su vehemencia en el uso del lenguaje y por sus posiciones intransables.

En términos de la regionalización, su opinión fue que el proceso para Valdivia había sido - según sus propias palabras - una "injusticia" y "una mordaza que frena las potencialidades de progreso". De la misma forma, calificó al centralismo como un "fenómeno que atenta contra el desarrollo de las sociedades". Y bajo su punto de vista, el proceso de toma de decisiones centralizadas generaba "decisiones cupulares, inconsultas y alejadas de realidad".

Con respecto al proceso de negociación que debía tener Valdivia con el gobierno central, su discurso siempre fue tajante. Observemos algunas de sus opiniones a lo largo del conflicto: "El diálogo está agotado en cuanto argumentos"; "La nueva región no es capricho". Si bien estas frases constan quizás de una consistencia declarativa normal por parte de una persona que esta de acuerdo con una demanda, cabe señalar algunas diferentes donde sí se puede apreciar su carácter maximalista. Por ejemplo, en la siguiente declaración: "Valdivia reclama para recuperar el sitial que le corresponde en el territorio patrio".

Finalmente, en cuanto a su posición frente a la solución del conflicto, se denota cierto cambio de tono en sus opiniones - sin dejar de ser maximalista - , pero sí dando paso a que las decisiones deben ser institucionalizadas. Ello se puede graficar de la siguiente manera: "El país enfrenta una excepcional oportunidad para ensayar verdaderamente un modelo de desarrollo territorial endógeno, participativo y no conflictivo" y asume una propuesta de solución bastante negociable: "División regional, es una opción para el desarrollo de una mejor administración y progreso".

En síntesis, este actor siendo durante todo el conflicto un maximalista, termina con una posición dispuesta para la negociación. Es posible que muchas de sus opiniones se justifiquen debido a la labor que desempeña como director de un medio de comunicación, ya que tiene la responsabilidad de interconetarse con las demandas de la comuna y la provincia a la cual se dirige. Además, se debe tener en cuenta que los medios de comunicación generan opinión pública y ponen en agenda noticiosa temas de interés para discutir, tanto por grupos de presión como por ciertas posiciones políticas. Por tanto, sus posiciones discursivas responden a su calidad de sujeto influyente en la opinión pública, y su visión maximalista del conflicto vendría a ser una estrategia comunicacional para entrar con fuerza en el debate público y generar apoyo en la base social. Queda claro que con esta estrategia genera 
mayor espacio para una negociación entre los actores locales y nacionales, apostando a una salida institucional del conflicto.

\section{Los negociadores}

Son aquellos actores que si bien algunas veces tienen posiciones maximalistas, denotan en su plano discursivo una actitud negociadora con respecto al conflicto, que se manifiesta en su capacidad de interrelacionarse con otros actores que son relevantes en el logro de la demanda. Utilizan sus posiciones de poder para influir en el accionar de las autoridades nacionales, regionales y locales. Y no obstante mantienen un trato amable con sus opositores, tratan de marcar las diferencias. Buscan siempre el entendimiento y utilizan las acciones de los maximalistas para mostrar las capacidades de respuesta de la comunidad organizada tras la demanda.

Responden a las estructuras nacionales de sus instituciones - tanto de partidos políticos como de gobierno - y están muy abiertos a las propuestas de solución que plantee el gobierno central. Esto se percibe en gran parte de sus discursos y hace coincidir con la opinión de Falabella (2001), quien señala que la relación existente entre las elites regionales, provinciales y locales con las nacionales, son de tipo clientela política. En otras palabras, la elite política provincial depende de la nacional, ya que esta última tiene mucho poder de decisión sobre la primera, tanto en su designación, como en la mantención de sus cargos. Sean estos parlamentarios o del gobierno interior. Lo recién señalado se debe tanto al diseño institucional del modelo presidencialista de gobierno, como de los partidos políticos, que son excesivamente centralizados.

\section{Exequiel Silva, diputado demócrata cristiano, en ejercicio}

Exequiel Silva desarrolla posiciones que lo caracterizan como un negociador con actitudes confrontacionales hacia otros actores políticos. Ello, se puede observar desde distintas perspectivas. Primero, por su posición política a favor del gobierno y de su partido, que manifiesta claramente en intervenciones como ésta: "no debemos actuar en forma populista y decir frases demagógicas con la finalidad de sacar dividendos políticos y atacar al gobierno y sus autoridades". Cabe señalar que la intervención anterior la realiza con respecto a las posiciones de los representantes de la derecha en el conflicto. No obstante, también tiene opiniones maximalistas cuando percibe el entorpecimiento a las gestiones realizadas para buscar una salida al conflicto - específicamente 
contra el entonces subsecretario Marcelo Schilling. Una de ellas es la siguiente: "vamos a seguir luchando porque esto se concrete a la brevedad posible". Opinión expresada en el marco de la disposición de recursos para el estudio sobre la factibilidad de que Valdivia sea una nueva región.

Considera que tiene un factor facilitador de importancia dentro de la negociación, al ser representante parlamentario del Partido Demócrata Cristiano por la zona. Lo cual, manifiesta de la siguiente manera: "tocaremos todas las puertas que sean necesarias, conversaremos con el ministro del Interior y hasta con el presidente de la República para que el compromiso que fue adquirido se cumpla, tenemos la capacidad y la llegada para hacerlo". En torno a lo anterior, hay que recordar que la militancia de los actores nacionales que se menciona en su discurso, son miembros del mismo partido.

Su posición frente al proceso de descentralización es clara, piensa que es totalmente perfectible, "esta descentralización no sólo significa mejorar la actual legislación de los gobiernos regionales y municipales, significa recoger los potenciales de cada uno para el país". Pero a la vez entiende que todo tiene sus fases, de hecho manifiesta "que la regionalización debe ser revisada por parte del gobierno bajo parámetros distintos". Opinión que le da al gobierno central un espacio como actor relevante dentro de la resolución de conflictos territoriales y un rol modernizador del proceso de descentralización.

Silva siempre se mostró como un ente activo dentro del espacio político, acusó en forma constante tanto a la derecha, como a quienes impedían en el Congreso que la Reforma Constitucional permitiera que Valdivia fuera región. Se debe recordar que en el gobierno de E. Frei Ruiz-Tagle, la propuesta de reformas constitucionales fue rechazada por la oposición, representada por Renovación Nacional y la Unión Demócrata Independiente. Esto quería decir que las aspiraciones valdivianas de ser región no serían cumplidas, debido a que para eso era necesario reformar el artículo 45, que establece el número de regiones del país. Es decir, eliminar el guarismo 13 e iniciar el proceso de reformas de las leyes orgánicas que regulan el sistema electoral y partidos políticos. Estos antecedentes, el diputado Silva siempre los puso en discusión pública tanto en la provincia de Valdivia como en el Congreso.

En términos de la solución del conflicto, la posicionó en gran medida a nivel político y en el Congreso, porque consideraba que la única viabilidad de la demanda estaba dada por las reformas a la Constitución política del Estado, ya que con éstas se garantizaba la factibilidad jurídico-legal de crear nuevas regiones. Por ende, concluía que era un tema de agenda legislativa y de discusión parlamentaria. Debido a esta posición, siempre planteaba que su estrategia era buscar el apoyo de todos los sectores políticos a la demanda valdiviana. Esto lo verbalizaba de la siguiente manera: "se buscará lograr algún tipo de 
compromiso por parte de los dirigentes máximos de las colectividades políticas para apoyar la idea de nueva región", opinión en el marco de la reunión Cumbre realizada en Valdivia con dirigentes nacionales de los partidos de oposición y gobierno con representación parlamentaria.

A través del tiempo es posible apreciar que la estrategia del diputado tuvo acciones concretas - como se mencionó anteriormente - , pero que por condiciones de la agenda legislativa del gobierno central y las posiciones, y la agenda legislativa de la oposición, no hubo ningún efecto real en este tipo de actos. Por el contrario, los resultados demostraron que la solución planteada por el gobierno nunca fue cambiar el plano institucional de la regionalización del país, ya que tenían claro que las reformas constitucionales serían difíciles de lograr; es más, con el tiempo las retiraron del Congreso y posteriormente de la agenda legislativa.

\section{Juan Enrique Taladriz, diputado de Renovación Nacional 1990-98}

Juan Enrique Taladriz mantuvo durante el conflicto posiciones distintas, que iban desde una visión maximalista hasta una negociadora. No obstante, se le ha integrado en el grupo de los negociadores, ya que fue derivando hacia posiciones más conciliadoras que terminaron respaldando las decisiones del gobierno.

Su opinión sobre la regionalización y los efectos causados en la provincia de Valdivia, los manifestó de la siguiente manera: "Nadie en Valdivia siente que pertenece a la décima región, esta tierra no tiene nada que ver con la que existe en Chiloé o con la que existe en Llanquihue" - y concluye - "el proceso de regionalización no fue favorable".

Por otro lado, cabe destacar su alta valoración a la condición de ser valdiviano, "nosotros pertenecemos a Valdivia, y nos da un sello, nos da un carácter de arraigo a la tierra". Con esta opinión se muestra el nivel de subjetivización de su postura, que se corrobora de la siguiente manera: "cualquier estudio nos dará la razón de que somos una región".

La posición maximalista de Taladriz la podemos encontrar en su percepción sobre el centralismo, que califica como algo "agobiante que proviene de la capital y que se ejerce con bastante fuerza y costumbre". Bajo el mismo marco de opinión anterior, destaca la conducta que adoptan muchos personeros frente al fenómeno del centralismo, "todos se someten dócilmente cuando el gobierno se muestra inerte en un acción", pero no aclara que cuando el gobierno toma una decisión todos la acatan. De hecho, como se muestra más adelante, 
el mismo diputado termina dando su respaldo a la propuesta de solución al conflicto que presentan las autoridades que ejercen el centralismo en Chile.

En términos de la negociación, sus opiniones tuvieron un carácter distinto. En algunas se denota su posición maximalista a pesar de avanzar rápido hacia el manejo de una negociación menos confrontacional con el gobierno. Primero manifiesta su desacuerdo con la actitud del entonces subdere Marcelo Schilling, "no mostró ningún apego a la causa". Y luego lo acusa en lo siguiente: "no tiene voluntad de dar atención a los problemas que tenemos los valdivianos"; con ello lo califica inmediatamente como un obstaculizador, y agrega cada vez - a manera de afianzar su posición - que detrás de la demanda valdiviana "hay unidad, hay coherencia entre lo que se dice sobre el tema en toda la gente de la provincia". Esto, con el fin de mostrar a la opinión pública que el representante de gobierno en cuestión, que a la vez fue elegido democráticamente, no es capaz de escuchar a sus electores. A lo anterior, agrega señales que en el transcurso del conflicto van mostrando su cambio progresivo de una posición maximalista acusadora, a una actitud derechamente negociadora. Ello se puede apreciar en la siguiente declaración: "se nos ha dilatado en el tiempo, deberíamos tener una decisión política, aunque no se implementará de inmediato".

Claramente, su posición negociadora se manifiesta en la solución del conflicto; está dispuesto a aceptar y a dar tiempo para lograr una solución que sea gradual y — más aún —, que sea propuesta por el presidente de la República. Lo cual verbaliza de la siguiente manera: "el presidente tomará una decisión de un proyecto específico o de una modificación que se haga en el contexto de la décima región" - y lo reafirma diciendo - "una decisión política, aunque no se implementará de inmediato, pero que orientará hacia qué parte vamos y eso es lo que debemos conseguir en los próximos años".

Gabriel Valdés, presidente del Senado 1990-96. Senador por la séptima circunscripción norte de la décima región, en ejercicio

Este es el actor más destacado dentro del conflicto por diferentes aspectos; dentro de ellos se pueden citar los siguientes: el alto cargo que desempeñó como parlamentario; su capacidad de influencia reconocida en el gobierno de E. Frei Ruiz-Tagle y por ser uno de los promotores de la idea "Valdivia, Nueva Región" en la provincia.

Lo anterior no significa que el análisis de su participación en el conflicto sea fácil de realizar. Esto se debe a que sus intervenciones públicas sobre el conflicto - por medios de prensa local y nacional - siempre fueron escuetas. Situación que impide un análisis de mayor profundidad. La cantidad de 
asociaciones y de afirmaciones-oposiciones en sus discursos son mínimas, lo que influye directamente en la calidad de las aserciones analíticas que se puedan realizar.

A modo de afirmación, se supondrá que lo expuesto recién se debió a su posición institucional como presidente del Senado y a su experiencia como parlamentario y canciller de la República, que lo hacen ostentar de una claridad en la acción de la opinión pública que muy pocos políticos logran hoy en día. Expresado en otras palabras, maneja muy bien los medios de comunicación y entiende que se utilizan para dar señales políticas y generar debate público en torno a un tema de interés.

Tampoco se debe olvidar, que en su condición de actor político - con una posición institucional y partidaria de alta influencia - hacía de estas condiciones un factor importante en el desarrollo de su actividad pública, tanto en la esfera nacional, como en la local. Ahora bien, en la esfera local resulta de interés analizar su gravitación en el conflicto sobre regionalidad de Valdivia, que estuvo dada por su carácter de ordenador, gestor y sistematizador de acciones relevantes.

Se observa - en gran parte de sus declaraciones - una relación directa con actores nacionales de alta relevancia, como es el caso del presidente de la República y el ministro del Interior. Cabe destacar que los personeros recién citados pertenecen a igual tienda política - Democracia Cristiana - que el senador Valdés. A lo anterior, se suma la utilización de influencias en organismos internacionales, como Naciones Unidas, donde por largo tiempo él desempeñó el cargo de subsecretario general, a cargo del Pnud. Estas relaciones de poder-influencia del personero en cuestión fueron claramente articuladas en parte del conflicto por los recursos para el estudio de factibilidad, realizado por los especialistas contratados por el Pnud y el gobierno.

Las relaciones de influencia con el Poder Ejecutivo eran de carácter cooperativo; mantenía buenas relaciones tanto con los actores locales, que defendían las posturas maximalistas de la demanda valdiviana, como con los aliados políticos y opositores al gobierno.

Cabe destacar que el senador Valdés sólo se enfrentó con el subsecretario de Desarrollo Regional M. Schilling, con quien no estrechó relaciones de cooperación - por el contrario - entraron en un debate sobre la utilización de recursos para el estudio de factibilidad. Esta situación conflictiva G. Valdés la resuelve a través de gestiones con el Ejecutivo, donde actúa pasando por encima del subsecretario y demostrándole su poder de influencia con el presidente y el ministro del Interior. Este hecho en particular marca la disposición del subsecretario con respecto al conflicto global. Actitud que podremos analizar más adelante, a través de sus intervenciones en la prensa local. 
Luego de lo descrito, resulta importante preguntarse: ¿por qué el senador Valdés toma como parte de su agenda política la demanda de regionalidad de Valdivia?

Primero, según el análisis, porque veía detrás de la demanda de los valdivianos que se aglutinaba una gran cantidad de actores influyentes del sector social-económico y político de la comuna y provincia de Valdivia.

En segundo lugar, él se encontraba muy cercano a un período de elecciones parlamentarias en las cuáles había decidido participar, y al observar la movilización organizada por la demanda de la nueva región, sus apreciaciones fueron de la siguiente forma: "fue extraordinario. Realmente estuvieron todos. Fue un acto cívico extraordinario e impactante". Realidad que le significa a G. Valdés tomar la demanda con mayor compromiso, situándola en un lugar destacado dentro de su agenda electoral. El comprometerse con la causa citada, en el marco de su propuesta reivindicativa de repostulación senatorial, le permitió - en gran parte - lograr su triunfo electoral, que tuvo las siguientes características: primera mayoría senatorial en la circunscripción, y una de las primeras mayorías senatoriales a nivel nacional, con un apoyo de $47 \%$ del electorado de la provincia.

En términos de la resolución del conflicto, su opción se inclina a que Valdivia sea región, siempre y cuando se mantenga bajo los claros marcos de la institucionalidad y las leyes del país, manteniendo su carácter personal de aglutinador de los intereses locales, provinciales y nacionales con respecto a la demanda. Tampoco ha dejado, hasta el día de hoy, el rol de promover acciones y gestiones con respecto a la demanda a todo nivel de influencia.

\section{Rabindranath Quinteros, intendente regional (1990-2000)}

El intendente Quinteros es uno de los actores del conflicto que tiene una posición de carácter facilitador; en ningún momento se presenta en oposición a la demanda valdiviana, por el contrario, se muestra como un líder conciente ante la extensión territorial de la región y de las dificultades propias que trae este fenómeno para su administración.

Una de las opiniones que sustenta su rol facilitador es la siguiente:

las aspiraciones para que Valdivia se convierta en región jamás han sido obstaculizadas por este intendente. A la inversa, muchas veces he animado el proceso asumido por los lideres sociales y políticos de la provincia de Valdivia, pues considero que están en su derecho de aspirar a alcanzar un objetivo que creen, de materializarse, muchos de los problemas aún existirían. 
En su condición institucional, como representante del presidente de la República en la región, hace que su visión esté limitada a las bondades políticas del gobierno central, y destaca a la vez, las acciones que éste ha tomado con respecto a la regionalidad de Valdivia, "desde hace años la provincia de Valdivia ha tenido la legítima aspiración de hacer la modificación de nuestra estructura regional, y por primera vez, también en la historia, y eso quiero agradecer al gobierno central, se ha tomado en serio este asunto". Es preciso recordar que la demanda de Valdivia ha sido tomada como un tema de preocupación por parte del gobierno central, en términos de la política de descentralización. Esto, debido a que tanto los actores nacionales como locales, lograron poner el caso en la agenda política durante un período de tiempo considerable.

Por tanto, es posible afirmar que en la posición desplegada por el intendente predominó la actitud de un observador pasivo ante las medidas del gobierno central. Con ello, cabe suponer que Quinteros no tuvo intención alguna de contraponerse con su jefe directo, el presidente de la República.

En torno a la resolución del conflicto, no se encontraron evidencias que permitan afirmar que el intendente desarrollara alguna propuesta o proyecto específico. Por el contrario, siempre predominó su rol facilitador, bajo el cual nunca dio a conocer una alternativa de solución como jefe de la región. Todo esto, a partir de la idea que la solución esperada por los valdivianos debía provenir desde el gobierno central y no del gobierno regional, ya que estaba claro que este último no tenía las facultades legales para resolver el conflicto.

\section{Jorge Vives, gobernador provincial (1994-2000)}

Jorge Vives es uno de los actores importantes dentro del conflicto por su posición institucional como gobernador provincial, representante del intendente y encargado del gobierno interior de la provincia.

En algunas ocasiones aparece formando parte de las acciones del Comité Nueva Región, donde manifiesta su apoyo político. Sin embargo, a la vez es vocero del gobierno central anunciando los pasos que éste seguirá en el conflicto. Tiende siempre a mantener una dualidad en sus acciones, manifestando al ente mayor las demandas de la provincia en su calidad de jefe territorial de la misma; pero en su condición de designado por el presidente de la República, administra las soluciones que el gobierno le presenta.

Su visión de la descentralización la enmarca en las líneas oficiales del gobierno, manifestando que "es un proceso que hay que evaluar". Considera que una descentralización efectiva es aquella en la que se consideran elemen- 
tos subjetivos, como lo es la cultura en el marco de un territorio. Ello lo verbaliza de la siguiente manera: "identidad regional como factor de descentralización". No obstante lo anterior, también reconoce que "las regiones muchas veces son una construcción política". Con estas opiniones, Vives formula su plan de acción política frente al conflicto, donde es posible apreciar tanto su posición conciliadora frente a los aspectos que pudieran estar en el centro de él, como en sus propuestas de negociación y de solución del mismo.

Con respecto a su visión del centralismo, se puede señalar que está muy dada por la orientación de su cargo. Tiene claro que el Poder Ejecutivo es relevante en cualquier tipo de iniciativa en el país.

Sobre la negociación, se acopla directamente a los resultados del estudio de los consultores y las presenta como alternativas negociables. Y respecto a lo mismo, cita que éstas son: "creación de una región; mayores atribuciones al gobierno provincial o dejar las cosas como están".

Considera que la solución real del conflicto tiene dos posibilidades, "una opción es dividir la región y crear la nueva región. Proceso de Reforma Constitucional" y la otra, "entregarle más disposiciones a la gobernación provincial". A la luz de su propuesta — que obviamente fue tomada del resultado del estudio - tuvo claro que la segunda era la más viable políticamente, ya que sólo dependía de la voluntad del presidente de la República. Lo cual, era más fácil de conseguir, considerando el engorroso proceso de Reforma Constitucional.

\section{Alejandro Foxley, presidente del partido Demócrata Cristiano}

Alejandro Foxley, en su calidad de dirigente nacional del principal partido político de la coalición de gobierno, tuvo un rol de "facilitador" de la demanda valdiviana. En general, se mostró abierto al proceso de negociación entre el gobierno central y los representantes de la provincia, y adquirió - según sus propias palabras - el "compromiso para hacer gestiones ante el gobierno". De hecho, reconoció que con respecto a la demanda "aquí se han dado argumentos de peso en función de lo que es la tradición regional en Valdivia", como también hizo un "reconocimiento de las potencialidades de la provincia de Valdivia para ser región".

No obstante, frente a la solución propuesta por los valdivianos de ser región, manifestaba que "una decisión como ésta no le corresponde a los partidos políticos", sino que "es una iniciativa política y administrativa del Estado". Con ello, si bien dejó en manos del gobierno la propuesta de solución, se comprometió como dirigente de su partido a que "la Democracia Cristiana va estar disponible para tener una discusión seria en el Parlamento sobre el 
tema". Bajo los argumentos recién citados, se puede observar que Foxley sólo potenció su carácter de persona influyente en las altas esferas de gobierno. Nunca entregó apoyo explicito a la comunidad valdiviana, respetó la institucionalidad y el centralismo como parte de su visión política, esgrimida en sus opiniones.

En términos de la solución del conflicto, consideró que la "iniciativa de carácter constitucional para permitir la creación de las regiones", debía tener un "consenso amplio en el Parlamento", y que éste se tenía que dar antes de iniciar el proceso legislativo de la iniciativa de reforma constitucional, porque creía que "si no hay acuerdo político previo de los parlamentarios y los partidos políticos, pueden surgir muchas aspiraciones a lo largo del país". Aportó además como tema a discutir, que "no hemos sido nosotros los que hemos puesto obstáculos a las reformas constitucionales". Presenta, a la vez, que las posibilidades de que Valdivia sea región pasan porque se concrete el paquete de reformas constitucionales propuestas por el Ejecutivo de ese entonces. Por tanto, se lleva la discusión a otro plano, uno que tiene que ver la negociación entre la derecha y el gobierno por las iniciativas de reforma de la Constitución. Ello deja claro que la demanda valdiviana entre actores nacionales se releva a una segunda instancia y la agenda legislativa con las reformas constitucionales se posiciona en el debate.

\section{Ángela Vivanco, presidenta del partido de Unión de Centro Centro Progresista}

Ángela Vivanco así manifestó su apoyo a la demanda: "creo que es legítima la aspiración de Valdivia de convertirse en región", ya que consideraba - según ella misma señaló - “que el proceso de regionalización se deberá tener que replantear, porque parece que ha quedado atrás en cuanto a sus parámetros". Con esto, asume como válido el que se den este tipo de demandas.

Sobre la resolución del conflicto, asume que la propuesta de los valdivianos "no es iniciativa parlamentaria, es de exclusiva responsabilidad del Ejecutivo"; por tanto, "el Ejecutivo debe presentar un proyecto de reforma constitucional" y en el caso de que fuera así, manifestaba "estaríamos dispuesto a apoyarlo". Al igual que la opinión de Foxley, sobre como resolver el conflicto, estima que éste está en manos del Ejecutivo y de su agenda legislativa. Ello lo sustenta en base a su conocimiento del diseño institucional del sistema político del país. Cabe destacar que no hace mención respecto al paquete de reformas constitucionales, que propone el gobierno, y que zanjaría la demanda de Valdivia. Con lo cual, reitera la posición de los actores nacionales de no conectar 
las demandas regionales o de su construcción de agendas, con los temas del país o de pauta nacional.

\section{Ricardo Núñez, presidente del Partido Socialista}

Ricardo Núñez sólo manifiesta, de la siguiente forma, su preocupación por el tema valdiviano: "he estado preocupado para que Valdivia sea región" y a la vez, reconoce la lucha de sus partidarios en el movimiento Valdivia Nueva Región; "conozco los anhelos y la lucha que los socialistas Valdivianos han dado por transformar a Valdivia en región".

Las palabras de Núñez, bajo el contexto dado por los lideres nacionales, fueron manifestaciones sin un compromiso político firme. En ningún momento planteó una propuesta que diese salida al conflicto; ni menos hizo un aporte interesante a la discusión sobre los fenómenos de centralización, regionalización y descentralización.

\section{Jorge Schaulsohn, presidente del Partido por la Democracia}

Para Schaulsohn, el conflicto tiene que ver con un proceso de evaluación de la regionalización en Chile, "es un tema que tiene que ver con todo lo que es la regionalización, no sólo con esta región". Y si bien es posible apoyar la apreciación recién planteada, se debe entender que en política, los conflictos de intereses detonan procesos que pueden llevar a plantear evaluaciones. Por tanto, se puede considerar que su opinión es de carácter distractivo para el estudio; no aporta información relevante para el análisis de actores.

\section{Los obstaculizadores}

\section{Los obstaculizadores abiertos}

Este tipo de actores posee como característica fundamental el entorpecer la gestión de la demanda, tienen posiciones encontradas con quienes la apoyan, y en gran medida, tratan de demostrar su poder frente a quienes los acusan de obtaculizadores.

Tienden siempre a minimizar al sector demandante; lo consideran de poca relevancia para la decisión gubernamental y cuestionan su origen. En el mismo ámbito, siempre le dan mayor importancia a la comparación con otros 
temas de orden nacional, que bajo su visión, debieran ser atendidos antes que la demanda en cuestión. Y por último, sus posiciones influyen directamente en la decisión final del conflicto.

\section{Marcelo Schilling, subsecretario de Desarrollo Regional (1994-2000)}

Marcelo Schilling fue considerado en el conflicto - por gran parte de los actores antes analizados - como un obstaculizador de la demanda valdiviana. De hecho, en el análisis discursivo de sus intervenciones, muestra claramente su poca voluntad política y administrativa para llegar a una solución del conflicto.

En términos de su posición sobre la descentralización, señala — según sus propias palabras - que la profundización del proceso "depende de las fuerzas endógenas de las regiones y no del gobierno". Con lo cual deja claro que si bien tuvo cierta visión del proceso, a medida que transcurrió el conflicto, tuvo que reconstruir paulatinamente su postura, y así dar paso a su condición de autoridad central, con mayor poder que las autoridades regionales y parlamentarias, debido al diseño institucional del sistema político del país.

La percepción que posee del centralismo se grafica claramente en esta opinión: "poder fijar las prioridades", a lo cual se suma su concepción instrumental de la política diciendo que "el problema de la nueva región de Valdivia nunca ha estado en los programas de la concertación". Se puede concluir que no es parte de la gestión política del gobierno de turno, al demostrar poca flexibilidad para ir incluyendo temas de interés público con respaldo ciudadano en la agenda y programa de gobierno. Esta percepción cambia en el tiempo, principalmente, por la capacidad de influencia que ejercen otros actores dentro del conflicto; quienes logran que la demanda de los valdivianos tome una relativa importancia para el gobierno y para su gestión como subsecretario de Desarrollo Regional y Administrativo en particular.

En términos de la negociación, Schilling siempre consideró que existían "problemas de estrategia política, comunicacional y de creación de fuerzas para lograr el objetivo". Es decir, para el personero recién citado, todo resultaba negativo en las acciones que buscaban sensibilizar a las autoridades nacionales con la demanda. Por otra parte, él siempre intentó minimizar la demanda y su apoyo, "nosotros no podemos tomar decisiones sobre aspiraciones de un conjunto pequeño de personas"; su concepto de gestión se vinculaba al principio que indica que la democracia debe privilegiar a las grandes mayorías.

Con respecto a la solución del conflicto, sus opiniones estuvieron marcadas por entregar pocas expectativas a los sustentadores de la demanda. Siempre planteó - según sus propias palabras — "que existían dificultades 
económicas, políticas, culturales y de otro orden" en relación a cualquier solución que se pudiera dar al problema. Y una vez que ya estuvo el estudio en curso, planteó que "el estudio puede dar un resultado contrario a las aspiraciones valdivianas". No obstante, creía que con los resultados del mismo se podía iniciar el proceso de toma de decisiones por parte del gobierno, en el cual nunca manifestó su voluntad para que participaran quienes encabezaban la demanda. Por el contrario, siempre indicó que "se llevará a cabo la recomendación que consideremos más pertinente". Finalmente, la propuesta fue entregarle mayores atribuciones a la gobernación provincial en su capacidad de decisión de inversión y de planificación; y la propuesta de una nueva región se postergó hasta que se discutieran las reformas constitucionales.

\section{Los obstaculizadores solapados}

Son aquellos actores que plantean, a nivel local, posiciones a favor de la demanda. Tienen una posición crítica de cómo se ha enfrentado el conflicto por parte de gobierno y habitualmente tratan - en sus discursos - de contraponer las posiciones de los demandantes con las acciones del Ejecutivo. Le otorgan toda la responsabilidad política al presidente de la República y plantean abiertamente que debe haber una propuesta de reforma constitucional para la solución del conflicto.

Pero ante sus posiciones y manejo del discurso público local, sus acciones se contradicen, ya que el gobierno una vez que presenta el paquete de reformas constitucionales, éstas ni siquiera se ponen en debate legislativo, porque fueron rechazadas públicamente por los actores en cuestión. Razón por la cual, se les ha calificado como obstaculizadores solapados.

\section{Jovino Novoa, presidente del Partido de la Unión Demócrata Independiente}

Para Jovino Novoa la descentralización es dar "mayor autonomía a las provincias y a las comunas", y en su calidad de opositor al gobierno de turno manifiesta que "se habla de regionalizar, se habla de descentralizar, pero en la realidad se hace muy poco". Con respecto a su opinión sobre el centralismo, señala que "en Chile el gobierno central todavía tiene mucho poder" y "que no hay descentralización del poder". Bajo las declaraciones anteriores se denota su posición política frente al tema, que es proclive a una mayor descentralización del poder en términos territoriales. Tiene claro que el diseño institucional del 
país es muy centralizado; situación que para él — en un periodo como opositor al gobierno - le incomoda mucho. Sin embargo, queda la duda si esta critica la realiza cuando fue parte de la gestión del gobierno militar, donde se desempeñó como ministro secretario general de la Presidencia.

En cuanto a la negociación, consideró que "el planteamiento de Valdivia es legítimo" y vuelve atacar al gobierno diciendo que "como no se hace nada, es lógico reclamarse región". Al parecer, si bien siempre tendió a mostrar sus diferencias, perfilándose como un duro contestador, gran parte del tiempo situó sus posturas en el marco de la institucionalidad.

De hecho, su propuesta de solución al conflicto estuvo marcada por una visión de agenda nacional. Ello lo verbaliza de la siguiente manera: "si el gobierno no lo prioriza en la agenda nacional, es muy difícil que este tema pueda ser materia de debate en todo Chile" - con lo que llegaba a la siguiente conclusión - "se requiere una decisión política del gobierno". Finalmente, plantea que "la UDI y RN solicitan que debe ser puesto como un tema prioritario por parte del gobierno". La lógica argumental del presente actor tiene mucho que ver con su experiencia en el cargo de gobierno que desempeñó y en la administración de la agenda pública. Es él único que plantea el tema de la priorización de la demanda de los valdivianos en la agenda de gobierno; su opinión demuestra que tiene claro que el modelo institucional del sistema político chileno, es altamente centralizado en el manejo de los temas de interés y de agenda pública, por tanto, considera que la presión debe apuntar hacia el gobierno central.

Con la convicción que plantea Novoa, una alternativa estratégica para llegar al logro de la demanda, pasa por estar en la construcción de los temas de interés en la gestión de gobierno. Y ello, debido a que el tema a la vez pasa por el mismo, y sólo se logra si la presión es fuerte por quienes llevan la causa. Por ende, siempre existe la posibilidad que una agenda regional sensible a las necesidades de su comunidad, que no cuente con los medios de presión suficientes para estar en la agenda nacional, no sea considerada por el gobierno de turno.

\section{Andrés Allamand, presidente del Partido Renovación Nacional}

Andrés Allamand, en sus opiniones sobre el conflicto, avanza directamente a las condiciones de la negociación. Plantea su apoyo a la nueva región de Valdivia, manifestándolo de la siguiente forma: "siempre he sido partidario de la nueva región". Inmediatamente pone en el tapete de la discusión que "no tiene ninguna posibilidad si el Gobierno mantiene el rechazo a la idea" y suma a estas opiniones 
lo siguiente: "la nueva región necesita de la voluntad política del gobierno de la concertación y el apoyo del presidente de la República". Insiste en que "si el gobierno no está dispuesto en avanzar en esta iniciativa serán esfuerzos en vano" y condiciona a las autoridades de turno diciendo que "la primera palabra la tiene el gobierno".

Con respecto a la solución del conflicto, dice que "es el pronunciamiento favorable del presidente de la República" el elemento necesario para el logro de que Valdivia sea nueva región. Éste actor repite la tendencia mostrada por los anteriores; es decir, reconoce que lo tratado es un tema de agenda nacional y de prerrogativa institucional del gobierno central.

Cabe mencionar que ambos personeros de la derecha - Novoa y Allamand - dieron mucha importancia al rol que debe ejercer el gobierno en la gestión para solucionar el conflicto. Sin embargo, nunca plantearon el rol de ellos como oposición al gobierno y sus posiciones frente al paquete de reformas constitucionales, a pesar de que estuvieron en contra de ellas, negándose a negociar. Actitud con la cual impedían su aprobación en el Congreso, ya que para llevarlas a cabo se necesita quórum calificado - tres cuartas partes de dicho poder - mayoría, que la concertación sólo lograba con el acuerdo de uno de los partidos de la derecha.

Ante lo recién señalado, se puede afirmar que si bien la voluntad de la derecha estaba empeñada a nivel regional de apoyar la demanda valdiviana, tenían claro de antemano que este compromiso jamás lo iban a cumplir, debido a que no estaban dispuestos a negociar el paquete de reformas constitucionales. Y no estaban dispuestos a negociar por razones de carácter de equilibrio y de beneficio político para el sector, ya que dentro de las reformas constitucionales se establecía la eliminación de los senadores institucionales y designados. Personeros que le permitían a la derecha mantener la mayoría en el Senado y con eso sobredimensionar su representación parlamentaria y no permitir a la concertación hacer las reformas necesarias para profundizar y llevar a cabo importantes transformaciones institucionales del sistema político del país. Como, por ejemplo, presentar cambios al sistema electoral binominal, y reformas tanto al consejo de seguridad nacional, como a la división política-administrativa de Chile.

En este caso, la derecha aparece potenciando el conflicto para poner en tela de juicio las acciones del gobierno y el sobredimensionado poder en la agenda pública. Sin embargo, y finalmente, ellos mismo estaban más condicionados a la agenda legislativa del gobierno con las reformas constitucionales y su intransable posición de no negociar, ni llevar a cabo ninguna de ellas. Lo cual trajo como efecto inmediato, que el Poder Ejecutivo se diera cuenta que 
no podía cumplir con la demanda valdiviana, independiente de las razones objetivas que se visualizaban en las propuestas de los mismos.

Por último, se puede afirmar que los obstáculos para la regionalización de Valdivia, son las reformas constitucionales y la postura en contra de ellas por parte la derecha política.

\section{La opinión de los técnicos}

A partir de la intervención de terceros actores, que estuvieron encomendados de entregar un informe para resolver e implementar una propuesta de acción para satisfacer la demanda de Valdivia, se llegó a la solución del conflicto.

Si bien se ha tratado en extenso el documento presentado por los consultores en el segundo capítulo de este estudio, se analizará cuales fueron sus opiniones a raíz de la visita de campo que ellos realizaron. Las manifestaciones citadas, fueron recogidas por el Diario Austral de Valdivia y pertenecen a Eduardo Dockendorf y Sergio Boisier. La tarea mencionada permitirá reconocer el prisma bajo el cual se observó el conflicto y como se planteó su propuesta de solución.

La visión que ellos comparten frente al proceso de descentralización del país - según sus propias palabras - es que "ha sido un proceso de maduración que se puede ver desde acá [Valdivia]" - y consideran que — "Valdivia es parte de este proceso" y "la situación de Valdivia es muy representativa de los fenómenos que pudieran estar ocurriendo en otras regiones". Estas opiniones marcan sus conclusiones en el documento entregado posteriormente a su visita de campo y poseen prejuicios - que en definitiva - van orientando el estudio. Plantean de ante mano que es un caso que no sólo podría estar ocurriendo en Valdivia, sino también en otras regiones. Por ende, cualquier solución que pudieran implementar, ya partía de una visión nacional y no regional como esperaban los valdivianos. Por otra parte, las opiniones recién planteadas se asemejan a la de ciertos actores nacionales a pesar que fueron emitidas antes de que se realizara el estudio. Sin embargo, no se percibe conexión alguna, ya que la base teórica de la consultoría fue desarrollada con anterioridad por parte de Sergio Boisier en la Cepal; por tanto, el sesgo de análisis de la información ya estaba consolidado.

En cuanto a la fortaleza de negociación que pudieron observar, manifiestan que la demanda tiene "un movimiento de una sólida base social", pero dejan claro que "hay alto grado de subjetividad en apoyar con mucha pasión la idea de configurar una nueva región"; consideran "que hay una homogeneidad y consistencia de mucha decisión en la idea de nueva región". Su observación en cuanto a la sensibilización de la demanda en la comunidad 
provincial, fue obtenida con mucha claridad; no obstante, siempre le dieron un alto nivel de subjetividad al apoyo de la iniciativa valdiviana.

En este caso, los consultores descartan de plano la subjetividad de las posiciones de la comunidad como algo relevante o de peso para la negociación del conflicto y de sus posibles soluciones. Aparentemente, no toman en cuenta que gran parte de los conflictos sociales se validan de forma social y política, en el plano de lo subjetivo, y se va al campo de lo objetivo a buscar las premisas necesarias que validen la racionalidad de las demandas. Es decir, si bien les llama mucho la atención las condiciones subjetivas - que claramente son aquellas que pueden hacer perdurar el problema por mucho tiempo - , no las consideran en sus opiniones, ni menos en las recomendaciones de solución al conflicto.

Finalmente, no esbozan ninguna solución posible al problema, sólo emiten las opiniones recién analizadas. Se puede afirmar que el rol de los consultores en el conflicto generó confianza en la comunidad valdiviana y en sus dirigentes, ya que el estudio fue una parte de la demanda que se ganó en el tiempo. Cabe destacar que ninguno de los lideres de la petición valdiviana cuestionó la constitución del equipo técnico, ni su procedencia. Situación que claramente dio lugar a los consultores para hacer sus propias apreciaciones y dejar espacio a que éstas sean influidas por el gobierno central. Tampoco se propuso la participación de un equipo técnico - como contraparte - que contara con la confianza de las organizaciones que encabeza la demanda, considerando que la provincia posee una universidad de prestigio que los podía proveer. Se cree - en cierta medida - que en el caso hubo muchas debilidades en una parte importante del proceso de darle objetividad a la demanda de Valdivia Nueva Región, situación que finalmente se expresaría en los resultados.

\section{Conclusiones del estudio}

El análisis realizado, desde la perspectiva de la negociación centro-región en el caso de la regionalidad de la provincia de Valdivia, muestra que las posiciones de los actores estuvieron determinadas por el diseño institucional del sistema político-administrativo del país. La constatación empírica deja ver qué más importante que las posiciones y reflexiones propias de cada uno de los personajes citados es el hecho de cómo estos respondieron a la definición de sus cargos. Un ejemplo claro de esto fue la relación permanente que estructuraban los actores entre la solución del conflicto y las acciones que debía desarrollar el presidente de la República para el logro de ella.

En general, el rol de los actores estuvo vinculado al reconocimiento de que el poder de decisión en lo político estaba en manos del presidente y del 
gobierno central, dando cuenta claramente que el resto de las estructuras del sistema político detenta el poder necesario para generar acciones e intereses programáticos del gobierno. Es más, se subentiende que el actor principal en la generación de resultados políticos es el mismo gobierno central; es decir, valga la redundancia, el fenómeno de concentración del poder - en el caso estudiado - genera estructuras con profundas diferencias de poder, que en esta situación se visualizan en la asignación a través del territorio del país.

Otra constatación fue el reconocimiento explícito - de una parte importante de los actores analizados - de que la construcción de la agenda pública era una prerrogativa exclusiva del gobierno y que en muy pocas oportunidades dependía de la capacidad de presión que ejercieran los actores. Lo cual, hace inferir de antemano que el gobierno es juez y parte en los conflictos que necesitan ser resueltos. De hecho es una conducta casi natural que se espere una solución por parte del gobierno central y que el mismo la implemente, independiente de las críticas regionales que se le hagan. Siempre se genera consenso entre los actores involucrados, ya sea motivados por el Poder Ejecutivo o por la acción casi mecánica de alinearse tras la solución entregando apoyo político, como fue en este caso la Agenda Pactada de Desarrollo de la provincia de Valdivia.

Por tanto, si hay condiciones culturales que determinen la conducta de los actores, el gobierno obtiene una gran movilidad y espacio para desempeñar su rol de "demandado" y hacer frente a los conflictos territoriales, sin tener grandes costos políticos. Para ello, puede hacer uso de las ventajas culturales a que responden los actores regionales, con el fin de llevar a cabo sus soluciones, ya que éste se encuentra favorecido por el diseño institucional del sistema político, tanto a nivel endógeno en la construcción político-administrativa del gobierno - que se caracteriza por su excesivo centralismo - como en el plano exógeno, donde el diseño institucional de los partidos políticos y gran parte de los grupos de presión, son altamente centralizados al igual que el Poder Ejecutivo. Cabe señalar que ambos son respaldados por la estructura jurídico-política.

A partir de lo anterior, se generan las condiciones necesarias para desarrollar y explotar, por parte de la elite nacional, el fenómeno cultural del clientelismo político que hace sobrevivir a estas clases regionales, que siempre esperan concesiones de sus homólogas a nivel nacional. Ello se puede constatar tanto en las designaciones de autoridades regionales a nivel de gobierno, como en la de candidatos a parlamentarios - a nivel de partidos políticos además de aquellas postulaciones designadas a la representación de diferentes organismos sociales.

Frente a esta constatación, queda de manifiesto que la negociación centro-región es un fenómeno territorial que depende mucho de los factores ya 
expuestos. Resulta ser muy vulnerable y — en cierta forma — pasa sólo por ser un acto reflejo de la elite nacional con su clientela política asentada en regiones. Con ello se puede señalar — metafóricamente — que el "dedo" largo del poder central, en gran parte de las instituciones políticas, sociales y económicas, filtra y ordena las demandas regionales, más derechamente las agendas regionales.

Si se llegó a estos resultados, cabe preguntarse qué pasó con el conflicto de regionalidad de Valdivia. Se puede decir que se dio un fenómeno de movilización política y social en la provincia por una demanda histórica de la elite provincial, asumida también por actores provinciales con altos niveles de influencia nacional. Sin embargo, dadas sus condiciones, tanto de representantes político-territoriales, como de miembros de agrupaciones políticas, no podían escapar a la lógica expuesta en los párrafos anteriores; es decir, su alta dependencia al centralismo. Con esto queda claro que la solución que presentara el gobierno sería acogida por esta elite territorial y contaría con su apoyo político. Por tanto, se puede señalar que si el gobierno central proponía que Valdivia fuese región, así sería. Y como el Ejecutivo dispuso como solución la conformación de una agenda pactada, ese fue el resultado que se obtuvo.

Ahora, si bien la solución fue un poco más allá de la situación que dio origen al conflicto, tampoco fue la decisión óptima porque entró a jugar el rol de negociación de las elites nacionales, sobre temas de agenda del país, que supeditaban a la demanda valdiviana. Ellas, en este caso, eran las reformas constitucionales - situación que determinaba la factibilidad de que el gobierno le pudiera dar la solución de región a los valdivianos. Esto responde a los obstáculos de fondo que tuvo la demanda, independiente a los apoyos recibidos, que vistos como experiencia de sociabilización de la demanda, fueron muy positivos.

Los obstáculos respondieron a posiciones políticas de derecha, que, entregando el apoyo a la demanda de Valdivia, jamás tuvieron la intención de negociar la agenda legislativa del gobierno. Con lo cual, este último se veía obligado a entregar una solución intermedia a los valdivianos, que en este caso fue la agenda pactada.

\section{Recomendaciones para una política pública de descentralización}

Estas recomendaciones tienen que ver con el sistema político y con la descentralización de poder, teniendo en cuenta el estudio de caso, que hizo referencia - en gran medida - al diseño institucional del país y a los efectos de éste en una situación de conflicto centro-región. En ningún caso las 
recomendaciones buscan ser el derrotero de una política descentralizadora, pero sí tienen implícitas las ambiciones de un simple ciudadano, que cree que fenómenos como el clientelismo político van abiertamente en contra de dar mayor participación a la ciudadanía en la gestión del Estado, tanto a nivel central como territorial. Así como a la vez, tampoco aportan a profundizar y mantener un modelo democrático de gobierno. De hecho, las recomendaciones apuntan a tratar de aminorar los efectos de este fenómeno y de fortalecer la participación de la gente en los gobiernos territoriales.

Si se entiende que una política pública de descentralización busca como meta - desde el punto de vista territorial - disminuir la brecha entre el Estado y la gente, en su ámbito político y administrativo, se debe potenciar la participación de la ciudadanía en las estructuras político decisionales; es decir, perfeccionar el sistema de participación en la generación de autoridades regionales, por medio de la elección directa del presidente y del consejo regional. Sin olvidar, eso sí, las críticas que se le hacen al diseño institucional del sistema político y la forma en que éste produce conductas de clientela política entre las elites.

Para conseguir lo anterior se debe dar paso a la reforma de sistema de partidos políticos, donde su conformación no se de por su representación nacional, sino que por su formación territorial. Es decir, que los representantes político-partidarios deben poseer como condición básica - antes de proponerse — el respaldo de la comunidad que piensan representar y prohibir la designación nacional de candidatos.

Se debe potenciar la instrucción y desarrollo de cuerpos directivos públicos y/o políticos, en regiones que permita nutrir a las elites regionales de miembros más autónomos a la influencia nacional. Concretamente, se deben crear colegios regionales de gobierno y gestión pública.

El Congreso debe legislar en función de una agenda pública nacional, construida a partir de la discusión entre los parlamentarios, el Poder Ejecutivo y gobiernos regionales y locales, con el objetivo de cautelar su dimensión territorial. Además, esta construcción de agenda debe estar orientada por principios de discriminación positiva. Ello significa que zonas más débiles al interior de una región o una región completa con respecto al país deben ser privilegiadas en el momento de tomar las decisiones, con respecto a otras poseedoras de mayores beneficios por parte de las políticas de desarrollo nacional.

En términos de los gobiernos regionales, se debe inhibir la reproducción de las conductas clientelisticas que capturan el sistema político. Esto se debe realizar tanto a través de formas de control ciudadano, como por la participación en la elaboración de los planes de desarrollo regional y local; además de la 
posibilidad de hacer pactos provinciales con mayor autonomía hacia el gobierno regional y central. Se debe considerar, también, que el consejo regional tenga, además de atribuciones fiscalizadoras y evaluativas de la gestión del presidente regional, la capacidad de destituirlo.

Quizás gran parte de las propuestas son totalmente discutibles, y es de esperar que se debatan para poder defenderlas y avanzar en una democracia territorial, que no esté por la homogeneidad del país, sino por su diversidad cultural, geográfica y política. Una democracia debe apuntar a la diferenciación y a la expresión de cada una de esas diferencias que existe en una sociedad.

De hecho, la estructuración centralizada de una agenda pública, de una elite política - que vive y disfruta de los goces del centralismo - y de una elite regional que se conforma con pequeños espacios de participación y de valoración, hacen que el modelo democrático no se pueda profundizar, ya que se generan equilibrios y fáciles consensos sobre el modelo de gestión del Estado. Por tanto, un opositor y crítico momentáneo a favor de la descentralización, sólo espera el desgaste del otro en el gobierno, para tener la oportunidad de vivir de las granjerías del poder centralizado, su institucionalidad y cultura.

Por último, acabar con los fenómenos mencionados pasa por hacer una refundación de principios y valores, que nazcan a partir de la discusión de un nuevo orden en la participación de la gente, donde ellos reconozcan su rol protagonista en el ámbito político. Además, deben comprender que la acción de gobernar no es ajena a ellos, sino que es parte de su condición de hombres y mujeres viviendo en sociedad; por consiguiente, que logren entender que la forma de gobernarse la construyen ellos mismos. En otras palabras, ponerse de acuerdo tanto en los medios como en los fines del sistema democrático. Estos acuerdos se deben lograr en la interacción con otros, bajo el marco de un lugar determinado que puede ser la manzana, el barrio, la comuna, la provincia o la región. Todas éstas, divisiones territoriales con las que se logra construir un modelo democrático más participativo, que permite a la gente evaluar y controlar la acción política a quienes han delegado el ejercicio de gobernar.

\section{Referencias bibliográficas}

BOISIER, S.; DOCKENDORFF, E.; MARINOVIC, E. Conflictos regionales y políticas públicas. Subdere, 1996.

CONARA (Comissión Nacional de la Reforma Administrativa). Chile hacia un nuevo destino. Documento n. 2, Santiago de Chile: Conara, 1976. 
CURLE, A. Conflictividad y pacificación. Barcelona: Editorial Herder, 1978.

DANA, D. Cómo pasar del conflicto al acuerdo. Santa Fé de Bogotá: Editorial Norma, 1992.

FALABELLA, G. Desarrollo diverso y proyecto país. In: MUÑOZ GOMÁ, O. (Ed.). Más allá del bosque: transformar el modelo exportador. Santiago do Chile: Flacso, 2001.

FISCHER, R.; URY, W. Sí... ide acuerdo!. — cómo negociar sin ceder. Santa Fé de Bogotá: Editorial Norma, 1991.

GOBERNACIÓN PROVINCIAL DE VALDIVIA. Corporación de Desarrollo de la Provincia de Valdivia (Codeproval). Agenda Pactada de Desarrollo. Valdivia, Chile, 1997.

LEDERACH, J. P. La regulación del conflicto social: un enfoque práctico. Ciudad de Guatemala: Comité Menonita, 1985.

STHOR, W. Metodología para la delimitación de las regiones en Chile, manual de planificación regional. Santiago de Chile: Pontificia Universidad Católica de Chile, Centro Interdisciplinario de Desarrollo Urbano y Regional, Cidu, 1969.

URY, W. iSupere el no! — Cómo negociar con personas que adoptan posiciones obstinadas. Santa Fé de Bogotá: Editorial Norma, 1994.

\section{Anexo 1}

\section{Listado de actores participantes del conflicto sobre regionalidad de Valdivia}

\section{Actores locales}

\begin{tabular}{|ll|}
\hline Actor & Cargo \\
\hline Raúl Basso & Presidente Comité Nueva Región Valdivia \\
Oscar Gayoso & Vice-presidente CNR \\
Enrique Larrain & Secretario CNR \\
Editor & Director Diario Austral de Valdivia \\
Silvia Oyarzún & Presidenta Comité Femenino CNR \\
Omar Assef & Delegado nacional PDC \\
Luis Matamala & Presidente Unión Comunal de JJ.V. \\
Luis Ibarboure & Presidente de Desarrollo de la Provincia de Valdivia \\
Carlos Silva & Presidente de la Asociación Gremial de Dueños de Camiones de Valdivia \\
Uldaricio Figueroa & Presidente PS \\
\hline
\end{tabular}




\begin{tabular}{|ll|}
\hline Actor & Cargo \\
\hline Sergio Espinoza & Coordinador del Consejo Económico y Social de Valdivia \\
& Concejo Municipal de Valdivia \\
Miguel Ramirez & Presidente de la Cámara de Comercio Detallista \\
Gonzalo Espinoza & Alcalde de Valdivia \\
Eduardo Shild & Presidente de la Cámara de Comercio e Industrias de Valdivia \\
Erwin Haverbeck & Ex-rector Universidad Austral de Chile \\
Robinson Ampuero & Presidente PDC \\
& Renovación Nacional Comunal \\
Mario Benavides & Directivo PS \\
\hline
\end{tabular}

\section{Actores provinciales}

\begin{tabular}{|ll|}
\hline Actor & Cargo \\
\hline Jorge Vives & Gobernador provincial \\
Exequiel Silva & Diputado \\
Juan Enrique Taladriz & Diputado \\
Juan Luis Gonzalez & Diputado \\
Gabriel Valdés & Senador - presidente del Senado \\
Octavio Cazaux & Alcalde de Futrono \\
René Tribiño & Alcalde de la Unión \\
Gastón Perez & Alcalde de Corral \\
Miriam Carrasco & Concejal de Mafil \\
& Directiva Provincial del PDC \\
& Capítulo Provincial de Valdivia de Municipalidades \\
\hline
\end{tabular}

\section{Actores regionales}

\begin{tabular}{|ll|}
\hline Actor & Cargo \\
\hline Rabindranath Quinteros & Intendente Regional \\
Omar Assef & Consejero Regional \\
Oscar Bosshardt & Consejero Regional \\
José Avalos & Jefe de División de Desarrollo Regional e Inversiones \\
\hline
\end{tabular}

\section{Actores nacionales}

\begin{tabular}{|ll|}
\hline Actor & Cargo \\
\hline Eduardo Frei Ruiz-Tagle & Presidente de la República \\
Carlos Figueroa & Ministro del Interior \\
Marcelo Schilling & Subsecretario de Desarrollo Regional y Administrativo \\
Ángela Vivanco & Presidente de la UCCP \\
\hline
\end{tabular}

continua 


\begin{tabular}{|ll|}
\hline Actor & Cargo \\
\hline Jovino Novoa & Presidente de la UDI \\
Andrés Allamand & Presidente de RN \\
Ricardo Núñez & Presidente del PS \\
Jorge Schausohn & Presidente del PPD \\
Alejandro Foxley & Presidente del PDC \\
Sergio Boissier & Consultor Pnud \\
Eduardo Dockendorf & Consultor Pnud \\
Esteban Marinovic & Consultor Pnud \\
\hline
\end{tabular}

\section{Anexo 2}

\section{Análisis de contenido}

\section{Raúl Basso, presidente de Comité Nueva Región}

\section{Nivel de contenido}

La conclusión que 20 años de diálogo con las autoridades máximas del país y líderes de los partidos políticos, no han sido suficientes para lograr la aspiración de ser región, pese a los argumentos convincentes y a las estadísticas que demuestran que en 20 años de regionalización la provincia de Valdivia ha ido quedando atrás en desarrollo económico, en población y en los niveles productivos.

(Se iniciará movilización social en la provincia, 5-11-1995)

Es que se han agregado razones. Se sabe que la policía de investigaciones tiene aprobado el traslado de la Jefatura Zonal de Valdivia. Un despojo más a los cientos que se han realizado desde que se inicio el proceso de regionalización. Según los directivos valdivianos, es una prueba más la falta de voluntad política del gobierno para escuchar los planteamientos de nuestra provincia. Si existiera tal voluntad, al menos se paralizarían este tipo de decisiones.

(Otro despojo para Valdivia, 24-11-1995)

Me parece que esto es una demostración clara de que la gente quiere que, efectivamente, el gobierno escuche la demanda de la comunidad valdiviana. Yo espero que no tengamos la necesidad de seguir recurriendo a estas manifestaciones masivas para que las autoridades se interesen en solucionar nuestros problemas.

(Basso; no estamos contra nadie, 1-12-1995) 
En el gran escollo del momento para concretar esta aspiración de los habitantes de la provincia de Valdivia que lleva más de 20 años se ha convertido Schilling (...) Sacar gente a la calle para que el presidente se de cuenta de que esta es una meta consensual en Valdivia y que no se trata de una coas que sólo interesa a un grupito de la provincia.

(Desconcierto en Comité Nueva Región, 10-8-1996)

La Comisión de Constitución, Legislación y Justicia del Senado aprobó con muy pocas modificaciones el proyecto manteniendo la mención de que el país está dividido en 13 regiones (...) todo esto pierde importancia sino tenemos la posibilidad de modificar la Constitución política; todo lo demás pierde sentido, porque el estudio de los especialistas externo que ya esta terminado forma parte de los muchos estudios que tiene la Subdere en cuanto a dividir la décima región. Pero, el hecho que el Ejecutivo mantenga el número 13 en el artículo 45, anula cualquier esperanza de obtener la Nueva Región Valdivia.

(Políticos nuevamente han dado vuelta la espalda a Valdivia, 7-4-1996)

La región pivotal no es ninguna solución para las inquietudes de la provincia, debido a que ellos de traspasar atribuciones no tiene ninguna validez de acuerdo a las disposiciones legales sobre la regionalización. De tal forma que la única alternativa para Valdivia, es la creación de la nueva región.

(La nueva región es la única alternativa, 14-9-1996)

\section{Oposiciones y asociaciones}

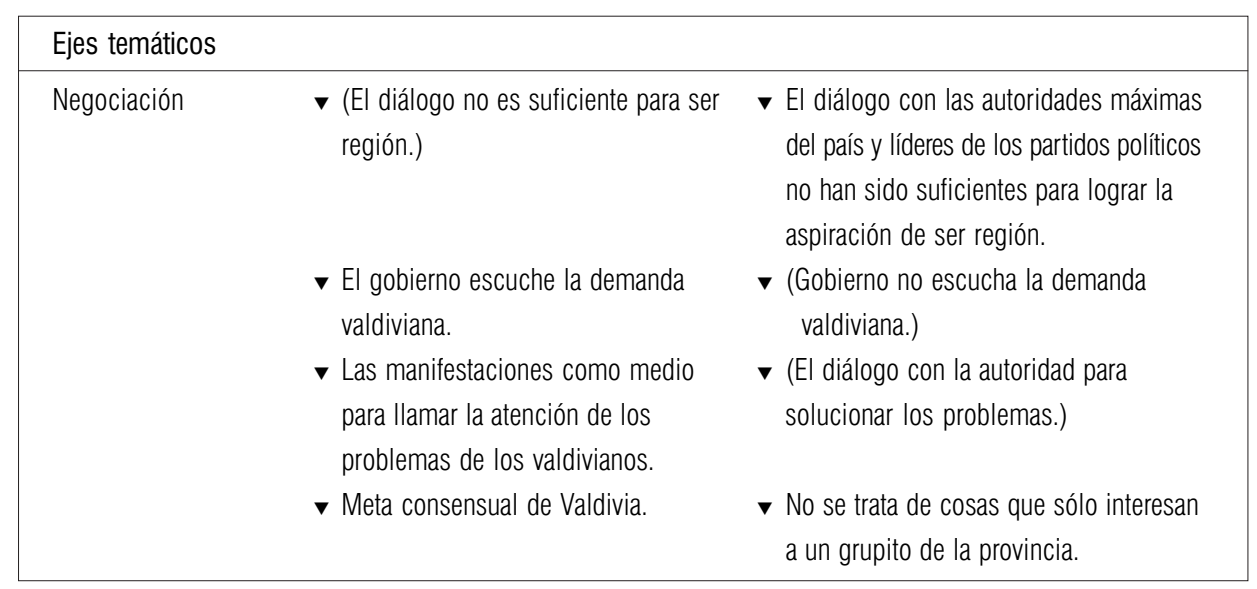




\begin{tabular}{|c|c|c|}
\hline Ejes temáticos & & \\
\hline \multirow[t]{2}{*}{ Regionalización } & $\begin{array}{l}\text { v (No ha sido factor de desarrollo para } \\
\text { Valdivia.) }\end{array}$ & $\begin{array}{l}\text { Los argumentos convincentes y las } \\
\text { estadísticas demuestran que en } 20 \text { años } \\
\text { de regionalización la provincia de Valdivia } \\
\text { ha ido quedando atrás en desarrollo } \\
\text { económico, en población y en los } \\
\text { niveles productivos. }\end{array}$ \\
\hline & - Un despojo de servicios públicos. & $\boldsymbol{\nabla}$ (Mayor cantidad de servicios públicos.) \\
\hline $\begin{array}{l}\text { Voluntad política } \\
\text { de gobierno }\end{array}$ & $\begin{array}{l}\text { จ No escuchan los planteamientos de } \\
\text { nuestra provincia. }\end{array}$ & $\begin{array}{l}\text { v Si existiera tal voluntad, al menos se } \\
\text { paralizarían este tipo de decisiones. }\end{array}$ \\
\hline $\begin{array}{l}\text { Percepción de las } \\
\text { autoridades y los } \\
\text { políticos }\end{array}$ & $\begin{array}{l}\text { vas autoridades nacionales son un } \\
\text { escollo para las aspiraciones } \\
\text { valdivianas. }\end{array}$ & $\begin{array}{l}\text { (Autoridades nacionales facilitadoras de } \\
\text { la demanda valdiviana.) }\end{array}$ \\
\hline & $\begin{array}{l}\text { - Los políticos no han respondido a la } \\
\text { demanda valdiviana. }\end{array}$ & $\begin{array}{l}\text { v (Políticos comprometidos con la } \\
\text { demanda valdiviana.) }\end{array}$ \\
\hline $\begin{array}{l}\text { Soluciones } \\
\text { del conflicto }\end{array}$ & $\begin{array}{l}\text { Va región pivotal no es ninguna } \\
\text { solución para las inquietudes de la } \\
\text { provincia. }\end{array}$ & $\begin{array}{l}\text { จ De tal forma la única alternativa para } \\
\text { Valdivia, es la creación de una nueva } \\
\text { región. }\end{array}$ \\
\hline
\end{tabular}

\section{Equivalencias y asociaciones}

V Veinte años de dialogo = no han sido suficientes para lograr la aspiración de ser región.

、 Salida de un servicio público = un despojo más que se ha realizado desde que se inició el proceso de regionalización.

- Si existiera voluntad política $=$ detención de los despojos.

$\checkmark$ Movilización $\rightarrow$ ser escuchado por las autoridades.

- Schilling, autoridad de gobierno = escollo para la demanda valdiviana.

v Sacar la gente a la calle $\rightarrow$ el presidente se dé cuenta que la demanda valdiviana es consensual.

v La solución $=$ Valdivia sea región. 